\title{
Tax systems and public borrowing limits in a fiscal union
}

\author{
Vladimir V. Dashkeev ${ }^{1} \cdot$ Stephen J. Turnovsky ${ }^{2} \oplus$
}

Accepted: 9 October 2021 / Published online: 9 January 2022

(c) Springer Science+Business Media, LLC, part of Springer Nature 2021

\begin{abstract}
This paper compares the implications of tax system and public borrowing limit asymmetries for the welfare cost of business cycles and interregional consumption risk sharing in a two-region fiscal union. We identify the welfare-improving and risk-sharing-improving designs of the regional tax systems and borrowing limits. We find that the choice of public borrowing limits is more consequential than is the choice of a tax regime for union welfare. It also serves as an argument for the harmonization of fiscal policies adopted in the fiscal union, as it would internalize fiscal externalities and improve consumption risk-sharing across the union regions. The key parameter determining the merits of alternative regional tax systems and possible limits to public borrowing in the fiscal union is the productivity of public good. Other aspects of the economy, such as the type of technology process, or the nature of the productivity shock do not affect the union public finance system design significantly. Extensive simulations suggest that if the productivity of public capital lies within the range of plausible empirical estimates, allowing both regions to have flexible borrowing limits and to choose whatever tax system they prefer will reduce the overall welfare costs of business fluctuations. However, for very low productivity of public capital, the welfare-improving regional public finance reforms that would prohibit public borrowing and tax labor income can produce limited benefits.
\end{abstract}

Keywords Balanced budget rules - Cost of business cycles · Fiscal union · Occasionally binding constraints $\cdot$ Productive public expenditures $\cdot$ Risk-sharing . Tax competition

JEL Classification F41 $\cdot$ E62 $\cdot$ H71 $\cdot$ H74 $\cdot$ H77

Stephen J. Turnovsky

sturn@uw.edu

Vladimir V. Dashkeev

dashkeev@seattleu.edu

1 Department of Economics, Albers School of Business and Economics, Seattle University, Pigott Building 424, Seattle, WA 98122, USA

2 Department of Economics, University of Washington, Savery Hall 343, Box 353330, Seattle, WA 98195, USA 


\section{Introduction}

The federalism structure of the United States grants a substantial degree of fiscal sovereignty to its constituent member states. As a result of this, it is characterized by substantial heterogeneity both on the revenue collection side, as well as in terms of the intergovernmental separation of expenditure functions. With respect to revenue collection, two sources of heterogeneity stand out: (i) the asymmetry of the tax systems adopted by individual state governments, and (ii) their degree of flexibility (or rigidity) with respect to requiring a balanced budget.

If one considers the three largest revenue-generating taxes in the U.S.A (labor income tax, capital income tax, and consumption tax), one will observe that of the five largest states, as measured by output, three (California, New York, and Illinois) collect most of their tax revenues from taxes on labor and capital income, while two (Texas and Florida) collect most of their revenues by taxing consumption. In some cases, neighboring states adopt polar-opposite tax systems. For example, Oregon does not collect a sales tax, while Washington State does not impose income taxes. At the national level, 59\% of the U.S. GDP is produced by states that have a tax system biased in favor of labor and capital income taxes. States in which the composition of tax revenue is tilted toward the consumption tax, rather than toward income taxes, generate $23 \%$ of the national output. ${ }^{1}$ This diversity is illustrated in Fig. 1. ${ }^{2}$

The second type of heterogeneous regional fiscal policy pertains to the range of public borrowing limits imposed across the U.S. states. To enable the analysis of these balanced-budget rules, states have typically been classified into one of the following two categories: (i) states having strict balanced-budget rules, and (ii) those with more flexible rules. This dichotomy is based on the Advisory Commission on Intergovernmental Relations index, ACIR (1987), which takes into account characteristics of the rules in each state. ${ }^{3}$ According to the accepted taxonomy in the fiscal-federalism literature, states having an ACIR index between 7 and 10 are classified as having strict borrowing rules, while those with an index between 0 and 6 have more flexible rules. The latter group consists of 13, mostly large, states (Fig. 2). Cumulatively, these states having less stringent balanced-budget rules produce $46.2 \%$ of the U.S. GDP. As discussed below, the states' balanced-budget

\footnotetext{
1 This taxonomy attributes states to one type or another once the difference of tax revenue shares generated by these two types of taxes exceeds 15 percentage points. Once the threshold is decreased to 5 percentage points, the shares become $27.3 \%$ and $65.1 \%$, correspondingly.

${ }^{2}$ Following the literature, we consider the continental United States for the present analysis. Alaska and Hawaii are omitted due to their idiosyncratic characteristics. Alaska has persistent surpluses driven by its small economic size and dependence on oil production, while Hawaii has a unique public education system.

${ }^{3}$ The index assumes values from 0 to 10 , so that Vermont (the only state without a balanced-budget requirement) is assigned 0 , while the states that require their budgets to be balanced at the end of the budgetary period are assigned 10 . States receive intermediate values according to other characteristics of their balanced-budget rules, such as provisions for carrying debt over to future budget periods, and if so, then for how long, or whether the borrowing limits are constitutional or statutory.
} 
rules have real effects on the states' fiscal policies, especially their stabilization policies over business cycles.

On the expenditure side, the intergovernmental asymmetry of the provision of public goods in the U.S.A is another distinguishing feature of its fiscal structure. About two-thirds of public consumption goods are provided by the federal government, while approximately three-fourths of productive public goods are supplied by its regional authorities. One can conclude from Table 1 that expenditure categories such as national defense, and parks and recreation, are characterized as public consumption goods, since they increase the utility of households. Economic affairs (infrastructure and utilities) and education increase the productivity of private factors, and hence are referred to as productive public goods.

In a recent paper, Dashkeev and Turnovsky (2018) analyze the welfare and risksharing characteristics of heterogeneous fiscal policy in a federal system, by comparing the performance of an economy in which regional governments are subject to differential borrowing limits, but with both regions imposing a consumption tax. However, with the larger share of tax revenues at the state level in fact being raised by income taxes, it is clearly important to allow for alternative sources of tax revenue collection by the constituent members of the union. Extending the framework in this way enables us to analyze the welfare and risk-sharing implications of diverse regional tax structures, and to compare them with the implications of the nature of the public borrowing constraint.

The fiscal union we consider comprises two regions. Aside from their fiscal characteristics, the regional economies are identical (in terms of their size, technology, and preferences). In equilibrium, both regions collect the same amount of tax revenues and provide an identical quantity of public capital. One regional government taxes consumption, while the other taxes labor income, in both cases of their respective constituents. Initially, we assume that both governments refrain from borrowing, allowing us to focus on the implications of the design of regional tax systems. But later the constraints on public borrowing are relaxed, and in fact the flexibility of the borrowing constraints turns out to be critical in our assessment of the merits of the various schemes. ${ }^{4}$

The framework serves the following objectives: (i) to analyze how the federalstate tax structure affects the transmission of productivity shocks across the union, (ii) to study the implications of the heterogeneous tax system in the union for welfare and interregional consumption risk-sharing, and (iii) to compare these consequences

\footnotetext{
${ }^{4}$ The specification of regional borrowing rules can be modified in various ways to reflect the experiences of regions in other fiscal unions. For example, one could allow unconstrained borrowing up to a threshold and increased cost of borrowing past this limit. Alternatively, one could specify borrowing limits as strict local debt limits imposed by the federal government, see, for example, Dai et al. (2019a, b), Huber and Runkel (2008). Such modifications would be tantamount to creating an intermediate (between the Flexible and Rigid governments) public finance system and, therefore, would not change the key insights of our study. This situation would, however, improve the performance of the union economy if it were to adopt this intermediate regime instead of the Rigid borrowing limit but deteriorate its performance if it were to replace the Flexible borrowing limit when the public good productivity is sufficiently high.
} 


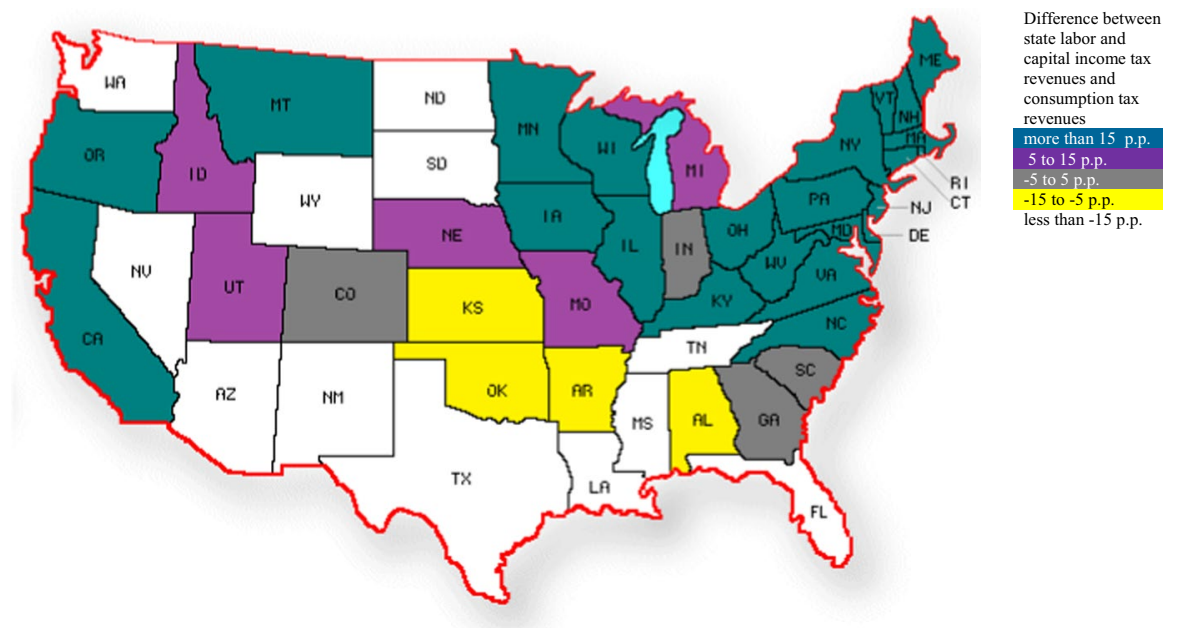

Fig. 1 Tax systems in the continental U.S. states Source: U.S. Census Bureau (2014), data for FY 2013. Note: This classification accounts for labor income taxes, capital income taxes, and consumption taxes, i.e. it ignores property taxes, excise taxes, severance taxes, stock transfer taxes, estate and gift taxes, and other miscellaneous taxes

of the tax system, with the corresponding consequences of alternative limits on public borrowing by states. We should note that the identification of the welfare-maximizing design of the union tax system should be interpreted as a constrained-optimal, rather than a Ramsey-optimal, policy. This is because we restrict the choice of tax instruments to be between the consumption tax and the labor income tax, as well as the magnitudes of their respective tax rates, as required to maintain tax-revenue neutrality.

Our analysis of the transmission mechanism shows that the asymmetric tax systems generate differential resource allocations across the union in the wake of an adverse economy-wide productivity shock, as well as a deterioration of risk-sharing in the fiscal union. This result hinges on both the revenue and the expenditure actions of the regional governments. On the revenue side, a region experiences a smaller reduction in tax revenues following the realization of a negative productivity shock if it imposes a consumption tax, rather than if it taxes labor income. This is due to the representative household's consumption-smoothing motive that ensures the regional government's tax-revenue smoothing. From the standpoint of public expenditures, the region in which the government collects more tax revenues can finance a greater supply of region-specific productive public goods, thereby enhancing the productivity of its capital and labor.

These two aspects of regional public finance cause a shift of resources from the less productive region to the more productive one, that is, from the region that taxes labor income to the region that taxes consumption. This migration of resources amplifies the interregional productivity differential, creating a wider consumption gap between the regions, which in addition deteriorates interregional consumption risk-sharing. In the context of the desirability of the inward shift of resources, this 


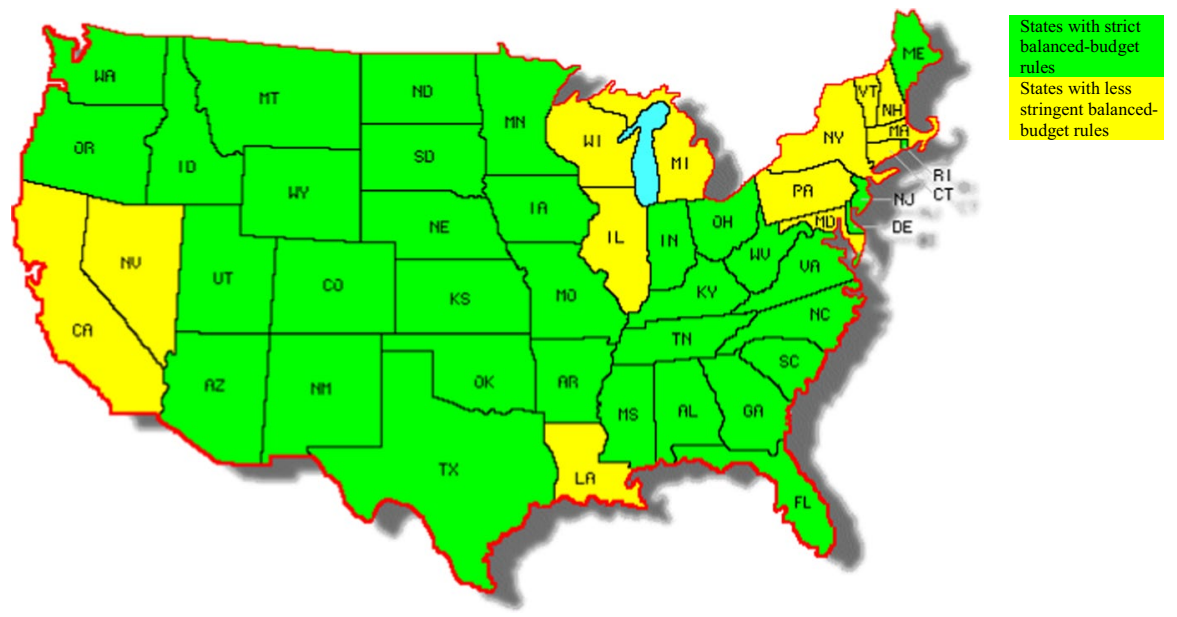

Fig. 2 Balanced-budget rules in the continental U.S. states. Source: ACIR (1987). Note: The yellow (lighter) color represents states with less stringent balanced-budget rules and corresponds to the ACIR index value of 6 and below. The green (darker) color represents states with strict balanced-budget rules and corresponds to the ACIR index value of 7 and above. The breakpoint value between the two types of the states is borrowed from the fiscal federalism literature (Color figure online)

Table 1 Functional composition of the federal and state government expenditures, 1977 $2000, \%$ of general government expenditures

\begin{tabular}{lcc}
\hline & $\begin{array}{l}\text { Federal expen- } \\
\text { ditures }\end{array}$ & $\begin{array}{l}\text { State } \\
\text { expendi- } \\
\text { tures }\end{array}$ \\
\hline Total expenditures & 47.8 & 52.2 \\
Consumption public goods & $\mathbf{3 7 . 8}$ & $\mathbf{2 0 . 9}$ \\
National defense & 29.9 & 0.0 \\
General public service & 2.1 & 6.0 \\
Health & 3.2 & 2.6 \\
Housing and community services & 0.9 & 1.2 \\
Income security & 0.5 & 2.3 \\
Public order and safety & 1.0 & 7.7 \\
Recreation and culture & 0.2 & 1.1 \\
Productive public goods & $\mathbf{1 0 . 0}$ & $\mathbf{3 1 . 3}$ \\
Education & 0.7 & 23.8 \\
Economic affairs & 9.3 & 7.5 \\
\hline
\end{tabular}

Source: U.S. National Income and Product Accounts, Sect. 3

The data in the table are consistent with the NIPA expenditures approach. Namely, transfers from the federal government to state governments are included in the expenditures of the federal government and transfers from governments to individuals are not reported as a part of government expenditures 
asymmetric design of the regional tax systems can be interpreted as regional tax competition.

Estimates of the productivity of public capital vary substantially; see Bom and Ligthart (2014). To allow for this variation and the associated uncertainty, we consider how the degree of risk-sharing varies with the productivity of public capital. We find that as the productivity of public capital increases, the differential impacts across the tax jurisdictions are amplified, and the adverse effects on risk-sharing are exacerbated.

To identify further the characteristic of the union tax system that improves both welfare and risk-sharing, we allow for two alternative regional tax structures and expose them to one-time productivity shocks. In the first tax regime both regions collect consumption taxes; in the second, they collect labor income taxes only. Two conclusions emerge.

First, we find that the adoption of any symmetric tax system eliminates fiscal externalities and improves interregional consumption risk-sharing. Second, we show that the productivity of public capital is the key factor determining the specific type of welfare-maximizing tax system. If the productivity of public capital is sufficiently high, the cost of business cycles to the union declines if its members tax consumption. However, if the productivity is sufficiently low, taxing labor income reduces the welfare cost to the union. Other aspects of the economy, such as the type of technology transmission process, or the type of shock (whether it is economy-wide or regional-specific), do not affect the tax system design. Moreover, in a fiscal union with very low, or low, public good productivity, the risk-sharing improvement is negligibly small.

Finally, we explore the welfare and risk-sharing properties of two types of fiscal unions: (i) one in which regional governments choose the nature of the tax to impose on their constituents and (ii) an alternative in which policymakers design public borrowing limits. Our findings indicate that for both interregional risksharing and the welfare costs of business cycles the public borrowing constraints imposed by regional policymakers are more important than is their choice of a tax system. This is because in the former case the asymmetric public borrowing limit arrangement is more detrimental to risk-sharing than is the asymmetric tax system. In the latter case, for asymmetric fiscal unions, the welfare-maximizing borrowing limit design can reduce the cost of business cycles to a greater extent than can the design of the welfare-maximizing tax system.

The remainder of the paper is structured as follows. Section 2 discusses related literature, while the following section describes the analytical environment and equilibrium conditions. The calibration underlying the numerical simulations is summarized in Sect. 4. Section 5 analyzes the effects of a temporary, adverse, productivity shock on regional performance. In addition, to gain further insights into the macroeconomic dynamics in the union, alternative degrees of public good productivity are considered. Section 6 explores in detail the welfare and interregional consumption risk-sharing properties of two types of fiscal unions: (i) a fiscal union in which regional governments choose the type of tax to impose on local households, and (ii) a fiscal union in which policymakers impose public borrowing limits. Section 7 concludes while technical details are relegated to the 
Appendix. Appendix 1 presents a derivation of the equation for net regional asset accumulation, Appendix 2 summarizes the equilibrium conditions of the model, and Appendix 3 contains some results derived under alternative assumptions regarding the specification of technology.

\section{Related literature}

From a theoretical standpoint, our paper contributes toward bridging the fiscal federalism and open economy macro literatures. The novelty of our approach is in providing a rich range of fiscal policy options to the various authorities, including the possible asymmetry of their policies.

The fiscal federalism literature has explored extensively a question with immensely important policy implications; specifically what are the welfare implications of federalization (or decentralization) of a state governance? But it has not reached a consensus on this matter. Two major participants in the debate, Charles Tiebout and Wallace Oates, provided opposing responses that were further developed by their followers. Tiebout (1956) suggested that decentralization leads to welfare improvement. The essence of his line of reasoning is the better ability of local governments to satisfy individual preferences for public goods. Combined with households' ability to relocate to a jurisdiction that more closely matches their preferences, decentralization leads to an aggregate welfare maximization in a federal state. Oates (1972) offered an alternative response, namely that more degrees of fiscal freedom lead to a decline in welfare. At the heart of his argument is the predatory tax competition or "race to the bottom." The original tax competition conjecture suggests that, in an attempt to attract mobile capital, local authorities play a capital income tax game that results in inefficiently low levels of capital income taxation and, therefore in the provision of public goods. ${ }^{5}$

In the fiscal federalism literature, this decentralization debate traditionally employs a deterministic general equilibrium framework, with a focus on equilibrium (steady-state) outcomes. In contrast, our analysis of the fiscal union adopts a real business cycle framework, thereby enabling us to incorporate elements such as consumption risk-sharing and other elements of contemporary stochastic macrodynamic analysis into the discussion of fiscal federalism. We view this to be an important contribution, since the flexibility of the model enables us to incorporate the realism of both high frequency realizations of transitory shocks and low frequency fiscal policy actions (such as changes of tax systems or public borrowing limits). Second, this methodology allows us to point out the importance of fiscal externalities brought about by these shocks for the design of the fiscal union.

Macroeconomic studies of monetary and fiscal integration were pioneered in the context of the optimal currency area (OCA) debate. Kenen (1969), whose work is

\footnotetext{
5 For a comprehensive review of the Tiebout-Oates debate and the literature that stemmed from it, see Oates (1999), Wilson (1999), and Oates (2005).
} 
the most relevant for the fiscal aspect of this study, argues in favor of fiscal integration in the presence of idiosyncratic shocks. In this scenario, a fiscal union can improve risk-sharing by means of intergovernmental transfers. Mundell (1961) and McKinnon (1963), the other founders of the OCA literature, motivated monetary integration by pointing out the benefit of greater stability of the union economies, after a realization of aggregate shocks. Results of the present analysis extend Kenen's argument for fiscal unification, by pointing out that members of a fiscal union can benefit from their participation in the union, following the realization of an aggregate shock scenario.

Recent theoretical studies of fiscal and monetary unification rely on the concept of interregional risk sharing to assess welfare performance of such unions. ${ }^{6}$ A common feature of the risk-sharing studies is the treatment of taxes as a given to recognize political constraints on their adjustment and to ensure model tractability. ${ }^{7}$ Farhi and Werning (2017) present a theoretical study of a fiscal union, in which governments provide contingent transfers to union members to improve their consumption smoothing. Dmitriev and Hoddenbagh (2019) study optimal design of a fiscal union as a function of the elasticity of substitution between goods produced by union members. Depending on the strength of the market power, welfare-improving fiscal union design requires a harmonization of tax rates or a contingent transfer system. In neither of these studies are productive public goods provided by the state.

Both of these fiscal union analyses assume symmetric environments and abstract from asymmetric regional tax systems, in which case aggregate shocks are of limited interest, and furthermore, there would be no benefit to fiscal unification in the absence of idiosyncratic shocks. Dashkeev and Turnovsky (2018) build a fiscal union model of the U.S. economy and analyze the risk-sharing effects of asymmetric public borrowing limits adopted by union members while incorporating the composition of the government expenditures.

The present study enriches the fiscal federalism and open-economy macroeconomics literature in additional ways, besides the risk-sharing aspect. We distinguish between types of public goods provided by the states. Although the differences between consumption and productive public goods are salient in the public finance literature, only a few authors have considered heterogeneous public good provisions in the decentralization debate. ${ }^{8}$ Notably, the role that productive public goods play in our study is contrary to Keen and Marchand (1997), who argue that welfare

\footnotetext{
${ }^{6}$ The interregional risk sharing concept is a counterpart of international risk sharing in open macroeconomics literature.

${ }^{7}$ This approach to modeling taxes has been utilized in some deterministic fiscal federalism studies as well; see, for example, Keen and Marchand (1997).

${ }^{8}$ See, for example, Zodrow and Mieszkowski (1986), Keen and Marchand (1997), Bayindir-Upmann (1998), and Arcalean et al. (2010).
} 
improvement can be achieved by a decrease in productive public goods provision combined with an increased provision of consumption public goods.

Next, we expand the policymakers' toolkit by not only allowing policymakers to impose taxes on labor income and consumption, but by also giving them a choice of public borrowing limits which, to the best of our knowledge, has not yet been done in the fiscal federalism literature. ${ }^{9}$ Traditionally, this literature focused on capital income taxes or property taxes and did not study balanced budget rules in a theoretical framework.

On the one hand, our findings support Oates in the decentralization debate. We report undesirable consequences of decentralization, which are not due to a race to the bottom, i.e., tax rates are time-invariant in our model. Rather, detrimental welfare effects materialize due to the under-provision of public goods and a corresponding interregional shift of resources that bring about risk-sharing deterioration. On the other hand, once public borrowing limits are introduced, we show that the choice of tax regimes by regional governments loses its importance and that tax decentralization does not deteriorate regional performance.

To reiterate, enriching the model (specifically, the fiscal policy toolkit) allows for new results, that are consistent with findings in other literature. For instance, Mendoza and Tesar (2005) focus on the long-run welfare consequences of tax games in a deterministic general equilibrium model representing the economy of the European Union. They allow a game in different types of taxes (capital income tax, labor income tax, and consumption tax). In some scenarios (absent of tax on consumption and when labor income tax substitutes capital tax), there is no race to the bottom. Yet, even if a race to the bottom occurs, it is welfare enhancing. ${ }^{10}$

\section{Analytical framework}

We begin by describing the underlying economic environment. This follows Dashkeev and Turnovsky (2018) who augment Backus et al. (1992) to include key public-sector features of a federal state. Special attention is paid to the provision of government consumption and capital goods, as in Turnovsky and Fisher (1995) and, more recently Economides et al. (2011). The framework we develop includes households, firms, and two levels of government-federal and regional. After describing the environment, equilibrium conditions for the economy are derived.

\footnotetext{
9 For macroeconomic studies of balanced budget rules see, e.g., Stockman (2001), Aiyagari, Marcet, Sargent, and Seppala (2002), and Bassetto and Sargent (2006).

10 Another example of policymakers' toolkit expansion leading to overturning the Oates hypothesis encompasses macroeconomic fiscal devaluation studies; see, e.g., Farhi et al. (2014) and Auray et al. (2017).
} 


\subsection{Environment}

We consider a federal state that comprises two regions, Region 1 and Region 2 . The regional economies are identical in terms of their size, technology, and preferences, but they differ in terms of their respective fiscal policies. Each region is populated by a representative household and a representative firm. There are no barriers to interregional capital mobility but labor is both supplied inelastically and is immobile between the regions. ${ }^{11}$

The government in the federal state comprises two levels. The first level is represented by the Federal government, which taxes capital income and labor income earned in both regions and in return provides a public consumption good equally available to both regions.

Regional governments represent the second levels of government. They are subject to two potential sources of asymmetry. First, they may employ different tax systems. Specifically, Region 1 imposes only a consumption tax, while Region 2 taxes only labor income, in both cases of their respective constituents. Both regional governments are assumed not to tax capital income. We make this simplifying assumption to facilitate interregional comparisons. Otherwise, the region with a nonzero capital income tax would have a lower equilibrium investment and capital stock, and, therefore, a lower consumption level. While the qualitative results of the analysis would be preserved, such asymmetry would make the comparison of regional performance less transparent.

The second possible source of asymmetry pertains to the rigidity or flexibility of the balanced-budget requirement. Accordingly, there is a range of fiscal regimes, corresponding to the alternative fiscal structures adopted by the constituent states. Our benchmark case where Region 1 taxes consumption, Region 2 taxes labor income, while both regions are subject to a rigid balanced budget rule, will be specified as $\boldsymbol{U}[(\boldsymbol{C}, \boldsymbol{R}),(\boldsymbol{L}, \boldsymbol{R})]$, with other regimes described correspondingly. In each case, the resources collected finance the purchase of a public capital good that the regional government provides to its local representative firm.

In describing the model, we shall focus on Region 1. Unless otherwise stated, Region 2's environment is symmetric with variables pertaining to that region being indicated by asterisks.

\footnotetext{
${ }^{11}$ The assumption of inelastically supplied and immobile labor serves to sharpen the asymmetry of interregional allocations created by heterogeneous regional tax systems and government expenditure composition on the time paths of capital accumulation and welfare. Preliminary work suggests that with labor mobility, the role of productive public goods and public borrowing limits for the cost of business cycles and risk sharing would stay the same as in the current setup. However, the structure of the welfare-maximizing tax system is likely to change. Endogenizing labor introduces additional dimensions into the analysis, reflecting the tradeoffs that households make between working, leisure, and migrating across jurisdictions. These are clearly important extensions that require separate detailed study.
} 


\subsubsection{Firms}

The representative firm in Region 1 hires labor, $L_{t}$, from its region, employs private capital, $K_{\mathrm{t}}$ and uses the region-specific publicly provided physical capital, $K_{\mathrm{RG}, \mathrm{t}}$, to produce a homogeneous consumption-investment good, $Y_{\mathrm{t}}$, according to the Cobb-Douglas production function. ${ }^{12}$

$$
Y_{\mathrm{t}}=Z_{\mathrm{t}} K_{\mathrm{t}}^{\alpha} \bar{L}^{1-\alpha}\left(K_{\mathrm{RG}, \mathrm{t}}\right)^{\alpha_{\mathrm{G}}}
$$

Output also depends on total factor productivity, $Z_{t}$, which is driven by the realization of a technology shock. Total factor productivities of the two regions are generated by the autoregressive process:

$$
\left[\begin{array}{c}
Z_{\mathrm{t}} \\
Z_{\mathrm{t}}^{*}
\end{array}\right]=\left[\begin{array}{cc}
\phi_{Z} & \phi_{Z Z^{*}} \\
\phi_{Z^{*} Z} & \phi_{Z^{*}}
\end{array}\right]\left[\begin{array}{c}
Z_{t-1} \\
Z_{t-1}^{*}
\end{array}\right]+\left[\begin{array}{c}
\epsilon_{\mathrm{t}} \\
\epsilon_{\mathrm{t}}^{*}
\end{array}\right]
$$

where $\phi_{Z Z^{*}}$ describes the technological spillover across the two regions. Section 4 imposes more structure on the matrix $\Phi$ in (2), based on existing empirical evidence.

Our choice of productivity shocks as being the source of exogenous disturbances in our model reflects the relationship of our paper to Backus et al. (1992) and the Real Business Cycle literature more generally. The consequence of productivity shocks are not only of natural interest, but they are also topical, especially in light of the COVID-19 experience. There is also the widely held view that they pose more challenging problems for stabilization than do demand shocks, which nevertheless are also potentially important. Accordingly, we have simulated a simplified version of our model in which we replace technology shocks with preference shocks, and can report that the key insights of our paper appear to remain. Specifically, the choice of a borrowing limit would still be more important than the choice of a tax system for the interregional consumption risk sharing and cost of business cycles, the asymmetry of regional tax systems would be detrimental for risk sharing, and the public good productivity would determine the welfare-maximizing regional fiscal policy design. But this preliminary investigation also suggests potential differences in the transitional dynamics from those presented here that could be usefully addressed in a modification of this framework.

\subsubsection{Households}

The representative household in Region 1 derives instantaneous utility from private and public consumption goods, $C_{\mathrm{t}}$ and $C_{\mathrm{G}}$, according to the isoelastic utility function (3),

\footnotetext{
$\overline{12}$ With an inelastic labor supply, whether a firm hires locally or nationally makes no difference.
} 


$$
\frac{C_{\mathrm{t}}^{1-\gamma}}{1-\gamma}+\frac{C_{\mathrm{G}}^{1-\gamma_{G}}}{1-\gamma_{\mathrm{G}}}
$$

where $\gamma>0$ is the inverse of the intertemporal elasticity of substitution for private consumption, and $\gamma_{\mathrm{G}}>0$ pertains to the public consumption good. Labor is supplied inelastically.

\subsubsection{Federal government}

The Federal government collects taxes on capital income and labor income at uniform rates, $\tau_{\mathrm{k}}$ and $\tau_{\mathrm{L}}^{\mathrm{FG}}$, from both regions, and provides an exogenously determined amount of a non-rival public consumption good, $C_{\mathrm{G}}$. The government apportions the procurement of the public good equally between the two regions. The federal authorities also impose lump-sum taxes on the residents of each region, $T_{\mathrm{FG}, \mathrm{t}}$ and $T_{\text {FG, }}^{*}{ }^{13}$ The budget constraint of the Federal government is as follows:

$$
\tau_{\mathrm{K}}\left(R_{\mathrm{t}} K_{\mathrm{t}}+R_{\mathrm{t}}^{*} K_{\mathrm{t}}^{*}\right)+\tau_{\mathrm{L}}^{\mathrm{FG}}\left(W_{\mathrm{t}} \bar{L}+W_{\mathrm{t}}^{*} \bar{L}^{*}\right)+T_{\mathrm{FG}, \mathrm{t}}+T_{\mathrm{FG}, \mathrm{t}}^{*}=C_{\mathrm{G}}
$$

where $R_{\mathrm{t}}, R_{\mathrm{t}}^{*}$ are the returns to private capital, $W_{\mathrm{t}}, W_{\mathrm{t}}^{*}$ are the wage rates in the two regions, both determined below.

\subsubsection{Regional governments}

As noted, in the benchmark regime the government of Region 1 taxes consumption at the rate $\tau_{\mathrm{c}}$, while the government of Region 2 taxes labor income at the rate, $\tau_{\mathrm{L}}^{\mathrm{RG}}$, in both cases of their respective residents. In addition, they impose lump-sum taxes, $T_{\mathrm{RGC}, \mathrm{t}}$ and $T_{\mathrm{RG} \mathrm{L,t}}^{*}$, respectively, and provide a productive public good, $I_{\mathrm{RG}, \mathrm{t}}$ and $I_{\mathrm{RG}, \mathrm{t}}^{*}$, to their local representative firm.

Poterba (1995) and Sorensen and Yosha (2001) find that, in the event of windfall tax revenues, states make little adjustments to their expenditures. Instead, they direct their budget surplus to finance their lump-sum transfers. ${ }^{14}$ The provision of public goods by regional governments is thus determined by their current tax revenues, and is exogenously capped at the steady-state level, $\overline{I_{\mathrm{RG}}}$.

Thus, in the case where regional governments are subject to strict public borrowing limits, (as in our benchmark regime) the public budget constraint for Region 1 takes the following form

$$
\tau_{\mathrm{C}} C_{\mathrm{t}}+T_{\mathrm{RGC}, \mathrm{t}}=I_{\mathrm{RG}, \mathrm{t}}, I_{\mathrm{RG}, \mathrm{t}}=\min \left\{\tau_{\mathrm{C}} C_{\mathrm{t}}, \overline{I_{\mathrm{RG}}}\right\}
$$

\footnotetext{
13 If negative, lump-sum taxes have an interpretation of transfers, such as welfare and social security payments. Since we wish to focus on the financial constraints facing the regional governments, we abstract from Federal government bonds. With the introduction of Federal lump-sum taxes, little is lost by this abstraction.

14 Also, some states use the unexpected tax revenues to reduce their public debt, which we abstract from in this study.
} 
while the budget constraint for the government of Region 2 is:

$$
\tau_{\mathrm{L}}^{\mathrm{RG}} W_{\mathrm{t}}^{*} \overline{L^{*}}+T_{\mathrm{RG}, \mathrm{t}}^{*}=I_{\mathrm{RG}, \mathrm{t}}^{*}, \quad I_{\mathrm{RG}, \mathrm{t}}^{*}=\min \left\{\tau_{\mathrm{L}}^{\mathrm{RG}} W_{\mathrm{t}}^{*} \overline{L^{*}}, \overline{I_{\mathrm{RG}}^{*}}\right\}
$$

Once the borrowing limit on regional governments is relaxed, the Flexible government that taxes consumption can issue 1-period risk-free bonds that can be purchased by the representative in-region and out-of-region households, $B_{\mathrm{RGC}, t+1}$ and $B_{\mathrm{RGC}, t+1}^{*}$, respectively, and pay an interest rate $R_{\mathrm{RG} \mathrm{C}, \mathrm{t}}$. The budget constraint, for the consumption-taxing regional government thus becomes:

$$
\begin{aligned}
& \tau_{\mathrm{C}} C_{\mathrm{t}}+B_{\mathrm{RGC}, t+1}+B_{\mathrm{RGC}, t+1}^{*}+T_{\mathrm{RGC}, \mathrm{t}} \\
& =\overline{I_{\mathrm{RG}}}+\left(1+R_{\mathrm{RGC}, \mathrm{t}}\right) B_{\mathrm{RG} \mathrm{C}, \mathrm{t}}+\left(1+R_{\mathrm{RGC}, \mathrm{t}}\right) B_{\mathrm{RGC}, \mathrm{t}}^{*}
\end{aligned}
$$

The budget constraint for the labor income-taxing regional government is modified analogously

$$
\begin{aligned}
& \tau_{\mathrm{L}}^{\mathrm{RG}} W_{\mathrm{t}}^{*} \overline{L^{*}}+B_{\mathrm{RG} \mathrm{L}, t+1}+B_{\mathrm{RG} \mathrm{L}, t+1}^{*}+T_{\mathrm{RG} \mathrm{L}, \mathrm{t}}^{*} \\
& =\overline{I_{\mathrm{RG}}^{*}}+\left(1+R_{\mathrm{RG} \mathrm{L}, \mathrm{t}}\right) B_{\mathrm{RG} \mathrm{L}, \mathrm{t}}+\left(1+R_{\mathrm{RG} \mathrm{L}, \mathrm{t}}\right) B_{\mathrm{RG} \mathrm{L}, \mathrm{t}}^{*}
\end{aligned}
$$

where $B_{\mathrm{RG} \mathrm{L}, t+1}$ and $B_{\mathrm{RG} \mathrm{L}, t+1}^{*}$ refer to the regional government bond holdings by the in-region and out-of-region households, and $R_{\mathrm{RG} \mathrm{L,t}}$ is the corresponding interest rate.

\subsection{Equilibrium conditions}

In this section we set out the equilibrium for the benchmark $U[(C, R),(L, R)]$ union.

\subsubsection{Firms}

The representative firm in Region 1 maximizes its profits, which yields the standard optimality conditions (7a) and (7b), equating the wage and the return to private capital to marginal productivities of labor and capital stock, respectively:

$$
\begin{gathered}
W_{\mathrm{t}}=(1-\alpha) Y_{\mathrm{t}} / \bar{L}, \\
R_{\mathrm{t}}=\alpha Y_{\mathrm{t}} / K_{\mathrm{t}}
\end{gathered}
$$

The rate of accumulation of the private capital stock is standard, where $\delta \in(0,1)$ denotes the depreciation rate.

$$
K_{t+1}=I_{\mathrm{t}}+(1-\delta) K_{\mathrm{t}}
$$

The rate of accumulation of public capital, $K_{\mathrm{RG}}$, is analogous to that for private capital, namely 


$$
K_{\mathrm{RG}, t+1}=I_{\mathrm{RG}, \mathrm{t}}+\left(1-\delta_{\mathrm{G}}\right) K_{\mathrm{RG}, \mathrm{t}}
$$

with similar conditions to (7a), (7b), (7c), (7d) applying to Region 2.

\subsubsection{Households}

The representative household in Region 1 chooses its rate of consumption, private capital accumulation, and holdings of private bonds, $B_{t+1}$ (paying interest $R_{\mathrm{PRI}, t}$ ), to maximize the utility function $(8)$ (where $\beta \in(0,1)$ is the subjective discount factor):

$$
\max _{C_{t}, K_{t+1}, B_{t+1}} E_{t}\left[\sum_{t=0}^{\infty} \beta^{t}\left(\frac{C_{t}^{1-\gamma}}{1-\gamma}+\frac{C_{G}^{1-\gamma_{G}}}{1-\gamma_{G}}\right)\right]
$$

subject to its budget constraint

$$
\begin{aligned}
K_{t+1}+B_{t+1}+\left(1+\tau_{\mathrm{C}}\right) C_{\mathrm{t}}= & \left(1-\tau_{\mathrm{L}}^{\mathrm{FG}}\right) W_{\mathrm{t}} \bar{L}+\left[\left(1-\tau_{\mathrm{K}}\right) R_{\mathrm{t}}+(1-\delta)\right] K_{\mathrm{t}} \\
& +\left(1+R_{\mathrm{PRI}, \mathrm{t}}\right) B_{\mathrm{t}}-\frac{\eta}{2}\left(B_{t+1}\right)^{2}-T_{\mathrm{FG}, \mathrm{t}}-T_{\mathrm{RG} \mathrm{C}, \mathrm{t}}+T_{\eta, \mathrm{t}}
\end{aligned}
$$

The constraint (9) states that the household allocates its disposable income from labor, capital, and returns on bond holdings to consumption, the accumulation of productive private capital, and purchases of the one-period, risk-free private bonds. Households pay bond-holding adjustment fees (brokerage fees) $\eta$ to financial intermediaries. With all bonds being riskless, convex bond-holding adjustment costs are necessary to ensure a determinate interior macroeconomic equilibrium and stationary responses of the economy to transitory shocks, with the quadratic costs being the most convenient. ${ }^{15}$ The fees are rebated to households via $T_{\eta, \mathrm{t}}$. Finally, the household pays lump-sum taxes to, or receives lump-sum transfers from, both levels of government, $T_{\mathrm{FG}, \mathrm{t}}$ and $T_{\mathrm{RG}, \mathrm{t}}$.

The representative household in Region 2 has a symmetric utility function that it optimizes subject to the budget constraint (10):

$$
\begin{aligned}
K_{t+1}^{*}+B_{t+1}^{*}+C_{\mathrm{t}}^{*}= & \left(1-\tau_{\mathrm{L}}^{\mathrm{FG}}-\tau_{\mathrm{L}}^{\mathrm{RG}}\right) W_{\mathrm{t}}^{*} \bar{L}^{*}+\left[\left(1-\tau_{\mathrm{K}}\right) R_{\mathrm{t}}^{*}+(1-\delta)\right] K_{\mathrm{t}}^{*} \\
& +\left(1+R_{\mathrm{PRI}, \mathrm{t}}\right) B_{\mathrm{t}}^{*}-\frac{\eta}{2}\left(B_{t+1}^{*}\right)^{2}-T_{\mathrm{FG}, \mathrm{t}}^{*}-T_{\mathrm{RG} \mathrm{L}, \mathrm{t}}^{*}+T_{\eta, \mathrm{t}}^{*}
\end{aligned}
$$

The solutions to the optimization problems yield Euler Eqs. (11) and (12) for households. In the absence of capital controls, these yield no-arbitrage conditions

\footnotetext{
15 The issue here is the familiar one of indeterminacy of equilibrium of a small open economy facing perfect world financial markets. Various approaches (offering varying degrees of sophistication) to closing such a model and thereby ensuring a determinate equilibrium have been proposed. The specification of quadratic fees, first introduced by Turnovsky (1985) and adopted subsequently by various authors (e.g., Benigno, 2009, Erceg et al., 2006, Ghironi, 2007, Cacciatore 2014) suffices in the present context.
} 
that equate interest rates on bonds with returns to private capital, adjusted for depreciation, and the tax on capital income.

$$
\begin{gathered}
\frac{\left(C_{\mathrm{t}}\right)^{-\gamma}}{E_{\mathrm{t}}\left[\left(C_{t+1}\right)^{-\gamma}\right]}=\beta E_{\mathrm{t}}\left[\left(1-\tau_{\mathrm{K}}\right) R_{t+1}+1-\delta\right], \\
\frac{\left(C_{\mathrm{t}}\right)^{-\gamma}}{E_{\mathrm{t}}\left[\left(C_{t+1}\right)^{-\gamma}\right]}=\frac{\beta\left(1+R_{\mathrm{PRI}, t+1}\right)}{\left(1+\eta B_{t+1}\right)}
\end{gathered}
$$

If regional governments adopt Flexible borrowing policies, the budget constraints for consumers subject to the consumption tax-financing regional government and its labor income tax-financing counterpart become, respectively

$$
\begin{aligned}
& K_{t+1}+B_{t+1}+B_{\mathrm{RG} \mathrm{C}, t+1}+\left(1+\tau_{\mathrm{C}}\right) C_{\mathrm{t}}=\left(1-\tau_{\mathrm{L}}^{\mathrm{FG}}\right) W_{\mathrm{t}} \bar{L}+\left[\left(1-\tau_{\mathrm{K}}\right) R_{\mathrm{t}}+(1-\delta)\right] K_{\mathrm{t}} \\
&+\left(1+R_{\mathrm{PRI}, \mathrm{t}}\right) B_{\mathrm{t}}+\left(1+R_{\mathrm{RG} \mathrm{C}, \mathrm{t}}\right) B_{\mathrm{RG} \mathrm{C}, \mathrm{t}}-\frac{\eta}{2}\left(B_{t+1}\right)^{2} \\
&-\frac{\eta}{2}\left(B_{\mathrm{RG} \mathrm{C}, t+1}\right)^{2}-T_{\mathrm{FG}, \mathrm{t}}-T_{\mathrm{RG} \mathrm{C}, \mathrm{t}}+T_{\eta, \mathrm{t}} \\
& K_{t+1}+B_{t+1}+B_{\mathrm{RG} \mathrm{L}, t+1}+C_{\mathrm{t}}=\left(1-\tau_{\mathrm{L}}^{\mathrm{FG}}-\tau_{\mathrm{L}}^{\mathrm{RG}}\right) W_{\mathrm{t}} \bar{L}+\left[\left(1-\tau_{\mathrm{K}}\right) R_{\mathrm{t}}+(1-\delta)\right] K_{\mathrm{t}} \\
&+\left(1+R_{\mathrm{PRI}, \mathrm{t}}\right) B_{\mathrm{t}}+\left(1+R_{\mathrm{RG} \mathrm{L}, \mathrm{t}}\right) B_{\mathrm{RG} \mathrm{L}, \mathrm{t}}-\frac{\eta}{2}\left(B_{t+1}\right)^{2} \\
&-\frac{\eta}{2}\left(B_{\mathrm{RG} \mathrm{L}, t+1}\right)^{2}-T_{\mathrm{FG}, \mathrm{t}}-T_{\mathrm{RG} \mathrm{L}, \mathrm{t}}+T_{\eta, \mathrm{t}}
\end{aligned}
$$

With the introduction of public debt, the maximization of household utility with respect to public bond holdings introduces additional Euler conditions. For example, for the bonds issued by the consumption-taxing government and acquired by households of Region 1, the corresponding Euler condition is:

$$
\frac{\left(C_{\mathrm{t}}\right)^{-\gamma}}{E_{\mathrm{t}}\left[\left(C_{t+1}\right)^{-\gamma}\right]}=\frac{\beta\left(1+R_{\mathrm{RGC}, t+1}\right)}{\left(1+\eta B_{\mathrm{RGC}, t+1}\right)}
$$

Taken jointly with Eqs. (11) and (12), Eq. (11*) augments the no-arbitrage condition to equate the return on public bonds to the return on private bonds, and adjusted return on private capital.

Finally, to satisfy the intertemporal budget constraint, the household is subject to the usual transversality conditions on capital and bonds. The former ensures that all capital is ultimately used and the latter implies that the household cannot finance its consumption indefinitely by borrowing.

The existence of complete asset markets and perfect risk-sharing implies that the ratio of the households' marginal utility in the two regions is constant over time. That is, the marginal utilities across the regions are perfectly correlated, as described by: 


$$
\frac{\left(C_{\mathrm{t}}\right)^{-\gamma}}{\left(C_{t+1}\right)^{-\gamma}}=\frac{\left(C_{\mathrm{t}}^{*}\right)^{-\gamma}}{\left(C_{t+1}^{*}\right)^{-\gamma}}
$$

Equation (13) provides a benchmark with which the incomplete markets of this model can be compared to determine how alternative tax systems affect deviations from perfect risk-sharing. We shall assess the risk-sharing characteristics of the alternative fiscal regimes in terms of the ratios of the regions' levels of consumption.

\subsubsection{Aggregation and interregional trade}

Combining the budget constraints of the households across the two regions, together with those of the Federal and Regional governments, yields the aggregate goods market clearing condition.

$$
Y_{\mathrm{t}}+Y_{\mathrm{t}}^{*}=C_{\mathrm{t}}+C_{\mathrm{t}}^{*}+I_{\mathrm{t}}+I_{\mathrm{t}}^{*}+C_{\mathrm{G}}+I_{\mathrm{RG}, \mathrm{t}}+I_{\mathrm{RG}, \mathrm{t}}^{*}
$$

In a multiregional economy, trade between the regions can occur and, in general, need not be balanced. In this case, the balance of trade (BOT) is:

$$
\mathrm{BOT}_{\mathrm{t}}=Y_{\mathrm{t}}-C_{\mathrm{t}}-I_{\mathrm{t}}-0.5 C_{\mathrm{G}}-I_{\mathrm{RG}, \mathrm{t}}
$$

Thus, for example, if Region 1 runs a trade deficit, its representative household issues private debt obligations to finance its private expenditures. Then the equation for the Region 1 net regional asset accumulation takes the following form ${ }^{16}$ :

$$
\begin{array}{r}
B_{t+1}-\left(1+R_{\mathrm{PRI}, \mathrm{t}}\right) B_{\mathrm{t}}=\frac{1}{2}\left(R_{\mathrm{t}} K_{\mathrm{t}}-R_{\mathrm{t}}^{*} K_{\mathrm{t}}^{*}\right)+\frac{1}{2}\left(W_{\mathrm{t}} \bar{L}-W_{\mathrm{t}}^{*} \overline{L^{*}}\right) \\
-\frac{1}{2}\left(C_{\mathrm{t}}-C_{\mathrm{t}}^{*}\right)-\frac{1}{2}\left(I_{\mathrm{t}}-I_{\mathrm{t}}^{*}\right)-\frac{1}{2}\left(I_{\mathrm{RG}, \mathrm{t}}-I_{\mathrm{RG}}^{*}\right)
\end{array}
$$

Finally, in the two-region economy, excess private bonds issued by one region are necessarily purchased by the other, and hence the bonds are in zero net supply:

$$
B_{\mathrm{t}}+B_{\mathrm{t}}^{*}=0
$$

To ensure intertemporal solvency of the regional government having the flexible borrowing limit, the following fiscal feedback rule is introduced:

\footnotetext{
${ }^{16}$ In a two region economy the positive net regional asset position of a given region corresponds to the net positive holdings of assets issued by another region by the residents of the former region. See Appendix 1 for details.
} 


$$
\begin{aligned}
\frac{T_{\mathrm{RGC}, \mathrm{t}}}{Y_{\mathrm{t}}} & =\frac{T_{\mathrm{RGC}, t-1}}{Y_{t-1}}+l_{\mathrm{st}}\left(\frac{B_{\mathrm{RGC}, t+1}+B_{\mathrm{RGC}, t+1}^{*}}{Y_{\mathrm{t}}}-\frac{B_{\mathrm{RGC} \mathrm{stst}}+B_{\mathrm{RGC} \mathrm{Stst}}^{*}}{Y_{s t s t}}\right) \\
& +l_{\mathrm{gr}}\left(\frac{B_{\mathrm{RGC}, t+1}+B_{\mathrm{RG} \mathrm{C}, t+1}^{*}}{Y_{\mathrm{t}}}-\frac{B_{\mathrm{RGC}, \mathrm{t}}+B_{\mathrm{RGC}, \mathrm{t}}^{*}}{Y_{t-1}}\right)
\end{aligned}
$$

where $l_{\mathrm{gr}} \in(0,1)$ determines the speed of the debt adjustment, $\iota_{\mathrm{st}} \in(0,1)$ determines the cyclicality of the adjustment, and the variable with the subscript st refers to its steady-state value.

\section{Calibration}

As a benchmark, we calibrate the model to approximate the fiscal structure of the US economy where one state taxes consumption and the other taxes labor income. All time-sensitive parameters are calibrated at an annual frequency, and their values are summarized in Table 2. ${ }^{17}$ The time discount factor, $\beta$, is set to 0.9615 . Setting $\gamma=2$ implies an intertemporal elasticity of substitution for private consumption of 0.5 , well within the estimated range reported by Guvenen (2006); $\gamma_{\mathrm{G}}=2$ is analogous for the public consumption good.

The share of national income that accrues to private capital, $\alpha$, is 0.36 , while the remainder accrues to labor. The productive elasticity of public capital, $\alpha_{\mathrm{G}}$, is a critical parameter and existing estimates are wide-ranging. The original estimate of this parameter obtained by Aschauer (1989), 0.39, exceeds the productivity of private capital and is generally regarded as extreme. Aschauer's work spurred numerous empirical studies that generated a broad range of productivity estimates for total public expenditures and its components. The overwhelming majority of the estimates obtained vary between 0.05 and 0.4 , with a consensus that some categories of public expenditures increase private sector productivity more than others. ${ }^{18}$ The most comprehensive study is Bom and Ligthart (2014) who conduct a metaregression analysis of 68 public good productivity studies published between 1983 and 2008. Their results range from 0.083 for the short-run estimates to 0.122 for the long-run estimates. When attention is restricted to regional productive public goods, the productivity estimate increases to 0.193 . Given the range of empirical estimates of the productivity of public investment, we choose $\alpha_{\mathrm{G}}=0.20$ as a baseline (medium) value and conduct extensive robustness tests with alternative values of the productivity parameter: 0.05 (very low), 0.10 (low), and 0.30 (high).

The depreciation rate is set at 0.10 for private capital, and 0.08 for more durable public capital. The Federal tax rates are typically estimated according to one of the alternative methods: the effective marginal tax rates using annual data following

\footnotetext{
17 Choosing a time unit of one year is natural, since regional governments typically budget on an annual basis.

18 Eicher and Turnovsky (2000) interpret low public good productivity as substantial congestion of the public goods.
} 
Table 2 Calibrated parameters

\begin{tabular}{lll}
\hline Parameter & & Value \\
\hline Preferences & & 0.9615 \\
$\beta$ & Discount factor & 2 \\
$\gamma$ & Inverse of intertemporal elasticity of substitution for private consump- \\
\multicolumn{4}{l}{ tion } & 2 \\
$\chi_{\mathrm{G}}$ & Inverse of intertemporal elasticity of substitution for public consump- \\
& $\quad$ tion & \\
Technology & & \\
$\alpha$ & Capital income share & 0.36 \\
$\alpha_{\mathrm{G}}$ & Elasticity of output with respect to public capital & $0.05,0.1,0.2,0.3$ \\
$\delta$ & Rate of depreciation of private capital & 0.10 \\
$\delta_{\mathrm{G}}$ & Rate of depreciation of public capital & 0.08 \\
Policy & & \\
$\tau_{\mathrm{K}}$ & Capital income tax & 0.305 \\
$\tau_{\mathrm{L}}^{\text {FG }}$ & Labor income tax, federal & 0.24 \\
$\tau_{\mathrm{L}}^{\text {RG }}$ & Labor income tax, regional & 0.09743 \\
$\tau_{\mathrm{C}}$ & Consumption tax & 0.10 \\
$l_{\text {st }}$ & Cyclicality of public debt adjustment & 0.1 \\
$l_{\mathrm{gr}}$ & Speed of public debt adjustment & 0.001 \\
$\eta$ & Bond-holding adjustment cost & 0.0025 \\
\hline & &
\end{tabular}

Joines (1981) and the effective average tax rates using quarterly series following Mendoza et al. (1994) and Jones (2002). For instance, using Jones (2002) methodology, Leeper et al. (2010) set their capital income, labor income, and consumption taxes at 38.4, 21.4, and 9.5\%, correspondingly. Using Joines (1981) approach to calculate effective marginal tax rates, Pappa (2009) sets the capital and labor income tax rates at the maximum of $30 \%$ and the consumption tax to $5-10 \%$. Guided by the above-cited papers, we set the Federal government's capital income tax rate, $\tau_{\mathrm{K}}$, to 0.305 and its labor income tax rate, $\tau_{\mathrm{L}}^{\mathrm{FG}}$, to 0.24 .

Turning to the tax rates set by the regional governments, the consumption tax rate, $\tau_{\mathrm{C}}$, is equal to 0.10 , virtually identical to that of the state of Washington. In the region where the local government taxes labor income rather than consumption, the labor income tax rate set by the regional government, $\tau_{\mathrm{L}}^{\mathrm{RG}}$ is $9.743 \%$, which is approximately the midpoint of the Californian state income tax schedule. That implies that the consolidated labor income tax rate is $33.743 \%$ for the households of this region. Setting the respective tax rates at these rates ensures identical tax revenues and public good provision across the regions. Finally, the speed of public debt adjustment, $l_{\mathrm{gr}}$, and the cyclicality of the adjustment, $l_{\mathrm{st}}$, are chosen following 
the SIGMA model and are equal to 0.001 and 0.1 , respectively. The bond-holding adjustment cost, $\eta$, is set to the frequently adopted value in the literature, $0.0025 .{ }^{19}$

Next, the bivariate exogenous productivity process must be parameterized. In the absence of information at the regional level, we draw on parameterizations employed at the international level. Even here, as Baxter and Farr (2005) have noted, it has proven difficult to estimate the parameters of the productivity process with much precision. Accordingly, we allow for two types of technology processes, to capture the likely range of parameter estimates:

First, we adopt the parameterization suggested by Baxter and Farr (2005) on the basis of empirical evidence of extremely high persistence of shocks and no interregional spillovers, which we transform to annual frequency as ${ }^{20}$

$$
\left[\begin{array}{cc}
\phi_{Z} & \phi_{Z Z *} \\
\phi_{Z * Z} & \phi_{Z *}
\end{array}\right]=\left[\begin{array}{cc}
0.996 & 0 \\
0 & 0.996
\end{array}\right]
$$

Second, Heathcote and Perri (2002) estimate a somewhat lower degree of persistence, but with positive spillovers, which we transform to annual frequency as

$$
\left[\begin{array}{cc}
\phi_{Z} & \phi_{Z Z *} \\
\phi_{Z * Z} & \phi_{Z *}
\end{array}\right]=\left[\begin{array}{ll}
0.888 & 0.091 \\
0.091 & 0.888
\end{array}\right]
$$

Finally, steady-state consumption, investment, and government expenditure shares are set at $62.4,17.9$, and $19.7 \%$ of national output, respectively (Table 3). ${ }^{21}$ We calibrate the share of the public consumption good provided by the federal government and the share of productive public goods provided by the regional governments to the corresponding shares of current and capital operations budgets in the national income, 15.3 and 4.4\%, respectively. This approach is adopted for a number of reasons. It is consistent with fiscal policy studies that address general government behavior. Moreover, it helps to mitigate the uncertainty regarding the attribution of different types of public expenditures to consumption and productive public goods. First, not all capital expenditures are productive. For example, Aschauer (1989), Finn (1993), and others show little productive effect of national defense expenditures and some smaller categories of government investment. Second, some authors argue that the current expenditures can be productive; for instance, Evans and Karras (1994) emphasize the productive role of current expenditures on education. Such arguments, combined with the fact that current expenditures on education amount to $41 \%$ of state expenditures, make it misleading to dismiss the entire current expenditures category as completely unproductive.

\footnotetext{
19 See e.g., Ghironi (2006), Cacciatore (2014). This parameter is critical in determining equilibrium bond holdings.

${ }^{20}$ Both the Baxter-Farr (2005) and the Heathcote-Perri (2002) process specifications are based on a quarterly frequency, which we have transformed to an annual frequency, since, as noted, this is a more appropriate time unit for our analysis.

21 The average values for 1977-2000 were calculated from the NIPA Table 1.1. The national output is defined as domestic absorption consistently with the market-clearing condition (14).
} 
Table 3 Steady-state shares of consumption, investment, and government expenditure of GDP

\begin{tabular}{llll}
\hline$C / Y$ & $I / Y$ & $C_{\mathrm{G}} / Y$ & $I_{\mathrm{G}} / Y$ \\
\hline $62.4 \%$ & $17.9 \%$ & $15.3 \%$ & $4.4 \%$ \\
\hline
\end{tabular}

The average values for 1977-2000 were calculated from the NIPA Table 1.1. The national output is defined as domestic absorption consistently with the market-clearing condition (14)

\section{Transmission of shocks}

The equilibrium conditions derived in Sect. 3, together with the parameters calibrated in the previous section, are used to solve numerically for the initial (unique) symmetric steady state. Decision rules and dynamic responses of the endogenous variables to productivity shocks are obtained using the first-order perturbation technique. The choice of the linear solution method is dictated by the compatibility requirements of the Guerrieri and Iacoviello (2015) occasionally binding constraints toolkit.

Using the numerical results, this section analyzes the effects of a technology shock, specified as a $1 \%$ decline in productivity. The reason for focusing on the negative shock is because the responses of different regional economies to a positive shock are identical, regardless of regional fiscal policy design, and therefore, positive shocks do not deteriorate risk-sharing. The similar dynamics that arise in that case stem from two factors. First, the absence of the intertemporal labor-consumption choice due to inelastic labor supply, and second, capping productive public good provision at the steady-state level. This latter assumption is consistent with the evidence, provided by the empirical fiscal federalism literature, that documents asymmetric behavior of regional fiscal policy over the business cycle (see, e.g., Poterba (1995) and Sorensen and Yosha (2001)) and incorporated in the regional budget constraints (5) and (6). ${ }^{22}$

In considering this adverse shock, this section focuses exclusively on the analysis of the macroeconomic performance of the benchmark fiscal union, $U[(C, R),(L$, $R)$ ]. According to this convention, the government of Region 1 finances its expenditures using the consumption tax, the government of Region 2 taxes labor income, and both regional governments are constrained by the rigid balanced-budget rule in financing their public goods.

In Sect. 5.1, the transmission of an adverse aggregate economy-wide productivity shock is studied, corresponding to the plausible, medium degree of public capital productivity, $\alpha_{\mathrm{G}}=0.20$. Sections 5.2 and 5.3 then analyze the responses of the economy to idiosyncratic declines in regional productivity. In both cases, technology processes of different types-without, and with, spillovers across regions-are considered. To gain further insights into the macroeconomic dynamic response of the union, and in particular its sensitivity to the productivity of the public good,

22 Simulations we have performed confirm this. 
variations in the key productivity parameter, $\alpha_{\mathrm{G}}$, from very low to high, are considered in Sect. 5.4.

\subsection{Aggregate productivity shock}

Regardless of the technology process specification, the model's endogenous variables respond to an adverse aggregate productivity shock in a similar qualitative, and almost identical quantitative, manner. Figure 3 plots the impulse responses in the absence of regional spillovers. ${ }^{23}$ Most variables are measured as percentage deviations from their respective steady-state levels. Because the equilibrium levels of bonds and balance of trade are equal to zero, their time paths are presented relative to regional output. The interest rate is reported as a percentage.

Initially, output and wages in both regions decline by the same amount, which is directly proportional to the size of the technology shock. Importantly, consumption declines less than do wages in either region, which implies higher tax revenues for the consumption-taxing region's government. Recalling that regional governments provide productive public goods, one can immediately conclude that the asymmetric tax revenues yield a productivity differential. This differential is further widened due to the shift of resources from the less productive labor income-taxing region to the more productive consumption-taxing region. Notice that the representative household of the former region holds a net positive asset position against the latter region. Moreover, private investment and capital stock in the labor income-taxing region lag behind those in the other region. The dynamics of the macroeconomic variables have an unfavorable consequence for the union, causing the interregional consumption risk-sharing to deteriorate.

\subsection{Productivity shock in consumption-taxing region (Region 1)}

Following the realization of region-specific shocks, consumption risk-sharing inevitably deteriorates, regardless of the presence of spillovers. However, the contrasting effects of the region-specific shocks is most dramatic when technology spillovers are absent. Figure 4 illustrates the realization of an adverse productivity shock in the consumption-taxing region (Region 1). The marginal productivity differential is tilted in favor of the labor income-taxing region (Region 2), hence, on impact, resources are shifted to that region from Region 1. Over time, as the impact of the technology shock declines, output, wages, consumption, and private investment in Region 2 gradually decline toward their respective steady-state levels in the wake of the shock.

The opposite applies to Region 1 macroeconomic variables. Moreover, its postshock convergence is slowed down by the lower tax revenue and depressed public good provision, which further deteriorates interregional consumption risk-sharing.

${ }^{23}$ Impulse responses for the specification with spillovers are available on request. 

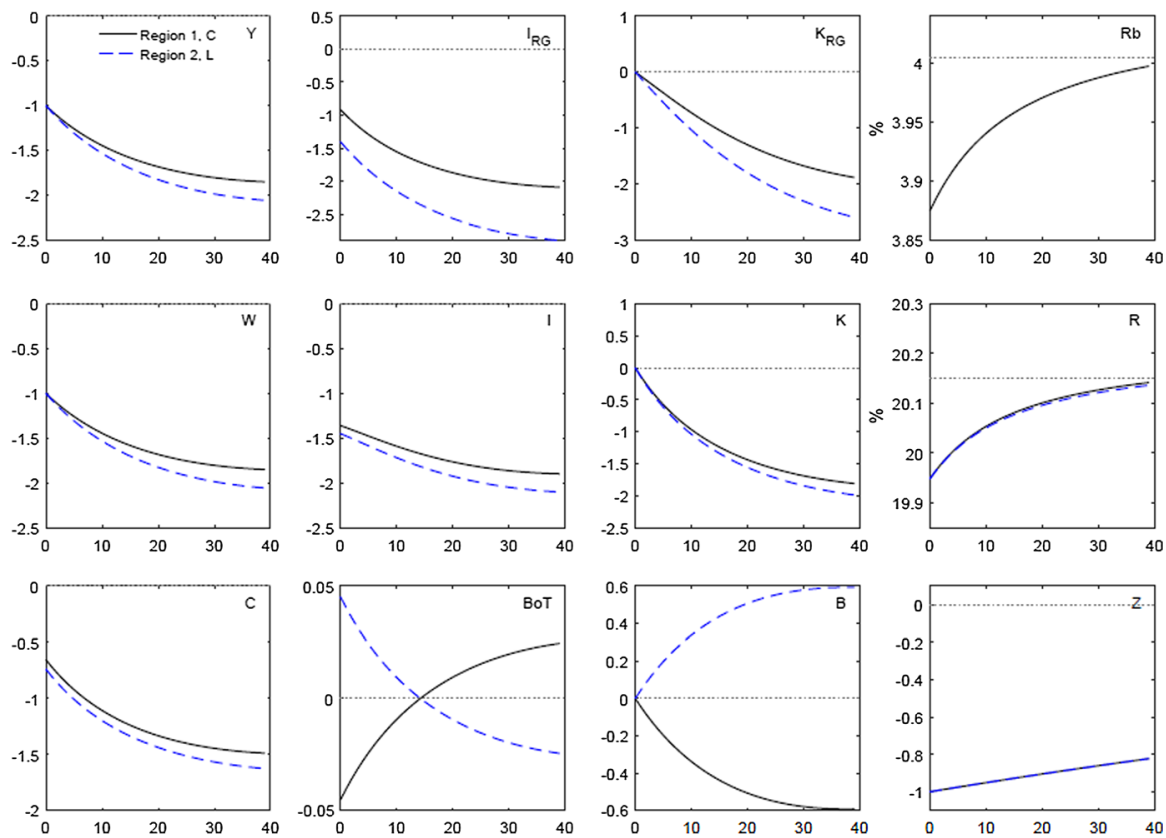

Fig. 3 Responses of the endogenous variables to the aggregate $-1 \%$ productivity shock to the $U[(C, R)$, $(L, R)]$ union. Notes: The $U[(C, R),(L, R)]$ fiscal union is considered. The technology process without spillovers is adopted. Productivity of public goods is medium. The vertical axis measures percentage deviations of the endogenous variables from their respective steady states with the exception of the balance of trade and bonds measured relative to the steady-state output as well as the interest rate measured as percentages. The horizontal axis measures periods after the shock

In the presence of technology spillovers, the negative dynamics of total factor productivity in the consumption-taxing region influences the economy of Region 2 (Fig. 7). The magnitude of this spillover productivity slowdown in Region 2 is by its nature smaller than the original shock realized in Region $1 .{ }^{24}$ Hence, risk-sharing deteriorates less than in the absence of spillovers.

\subsection{Productivity shock in labor income-taxing region (Region 2)}

Figure 5 illustrates the dynamics of the endogenous variables following the realization of an adverse productivity shock in Region 2, in the absence of interregional technology spillovers. ${ }^{25}$ Similar to the scenario of idiosyncratic shocks to Region 1 , the region directly affected by the shock experiences a contraction and an export

\footnotetext{
24 See Eq. (20).

25 As shown in the preceding subsection, risk sharing deteriorates to the greater extent once the technology spillovers are allowed. Figure 8 presents impulse responses for the case with the technology spillovers.
} 

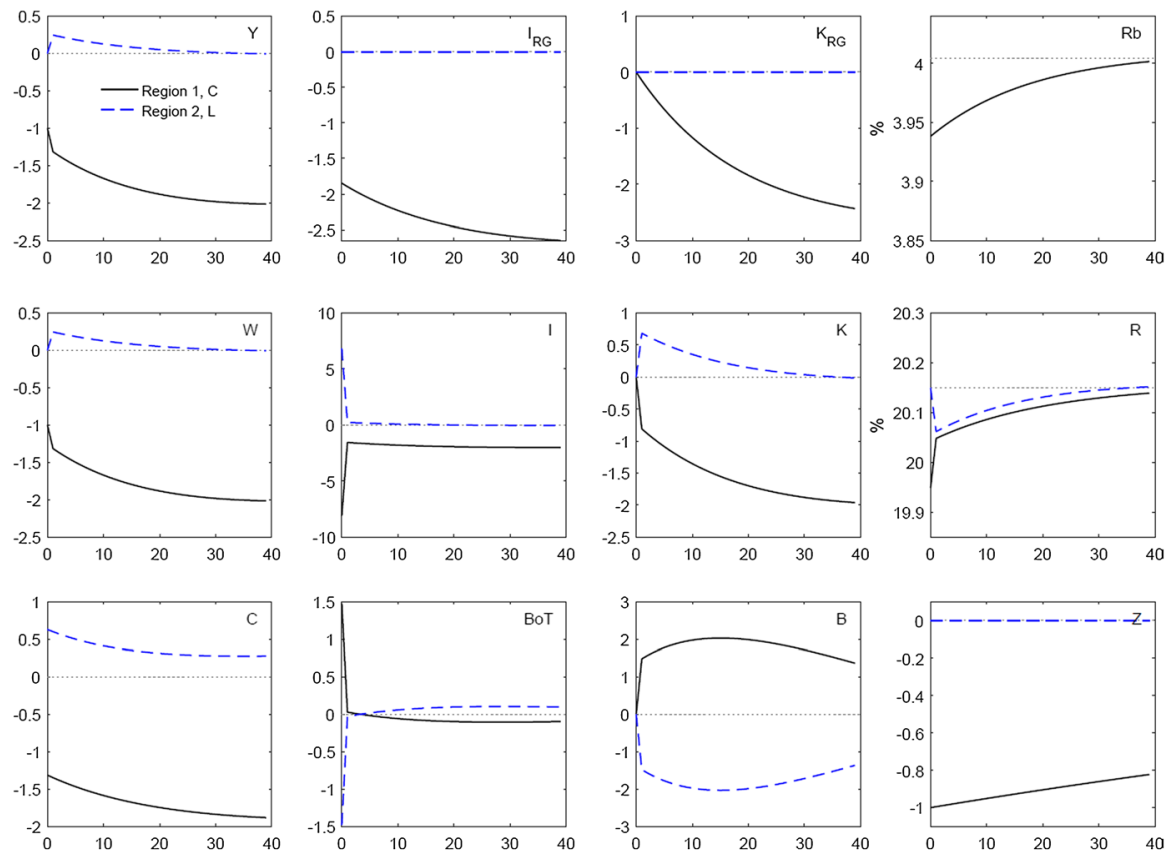

Fig. 4 Response of the endogenous variables to the idiosyncratic $-1 \%$ productivity shock to the $(C, R)$ region. Notes: The $U[(C, R),(L, R)]$ fiscal union is considered. The technology process without spillovers is adopted. Productivity of public goods is medium. The vertical axis measures percentage deviations of the endogenous variables from their respective steady states with the exception of the balance of trade and bonds measured relative to the steady-state output as well as the interest rate measured as percentages. The horizontal axis measures periods after the shock

of resources. The under-provision of public capital amplifies the recession and the deterioration in risk-sharing.

The distinctive feature of the productivity shock occurring in the labor incometaxing region rather than in the consumption-taxing region is the deeper contraction of the regional tax revenues in the region directly impacted by the shock. This is because the consumption-taxing region has a more stable tax revenue flow due to the representative household's consumption-smoothing motive. Hence, productivity in Region 1 remains higher following an idiosyncratic shock to that region as compared to the comparable situation in Region 2.

\subsection{Sensitivity to public good productivity}

This section briefly reports the sensitivity of the macrodynamic equilibrium to the productivity of public capital, demonstrating how this is a key parameter in 

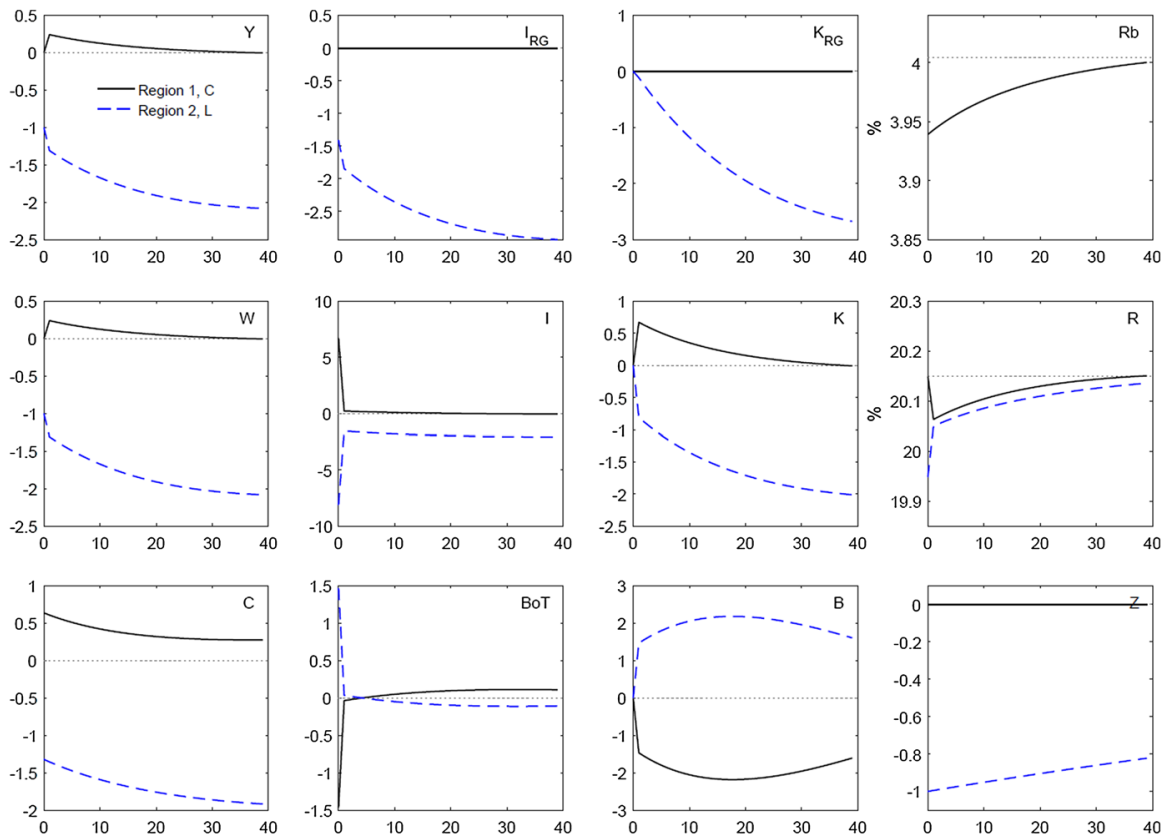

Fig. 5 Response of the endogenous variables to the idiosyncratic $-1 \%$ productivity shock to the $(L, R)$ region. Notes: The $U[(C, R),(L, R)]$ fiscal union is considered. The technology process without spillovers is adopted. Productivity of public goods is medium. The vertical axis measures percentage deviations of the endogenous variables from their respective steady states with the exception of the balance of trade and bonds measured relative to the steady-state output as well as the interest rate measured as percentages. The horizontal axis measures periods after the shock

determining the degree of risk-sharing in the fiscal union. As the productivity of public goods increases from low to high $\left(\alpha_{\mathrm{G}}=0.10-0.30\right)$, the interregional asymmetry of allocations sharpens (Fig. 6), and the migration of resources across regions increases. This process occurs in the scenarios of both aggregate and idiosyncratic shocks.

However, the results change if the productivity of public capital is extremely low $\left(\alpha_{\mathrm{G}}=0.05\right)$. To see this, consider the aggregate shock realization. Although output still remains higher in Region 1 as before, the time path of consumption in Region 2 now marginally exceeds that of Region 1 which translates into modestly higher welfare of the representative household in Region 2 (see Table 4).

The intuition underlying this finding reflects the fact that public investment in Region 2 decreases much more sharply than in Region 1, whereas there is no such wide interregional disparity for private investment between the two regions. While higher tax revenues in Region 1 support the provision of a higher level of the regional productive public good, its low productivity does not justify the withdrawal of resources from private use. The extra output produced in Region 1 is channeled to the provision of the public good with very low productivity. This inefficient behavior determines lower consumption and welfare of the representative household in Region 1 relative to 

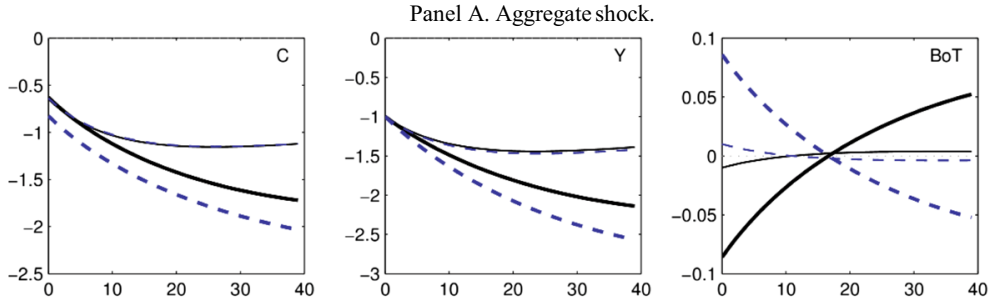

- Region (C,R) $\alpha_{G}=$ high; - - - Region (L,R) $\alpha_{G}=$ high; —_Region (C,R) $\alpha_{G}=$ very low; - - - Region (L,R) $\alpha_{G}=$ very low Panel B. Idiosyncratic shock to the $(\boldsymbol{C}, \boldsymbol{R})$ region.
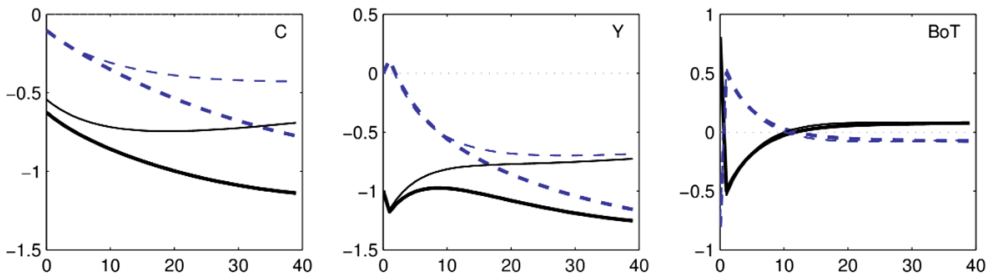

- Region (C,R) $\alpha_{G}=$ high; - - - Region (L,R) $\alpha_{G}=$ high; ——Region $(C, R) \alpha_{G}=$ very low; - - -Region (L,R) $\alpha_{G}=$ very low

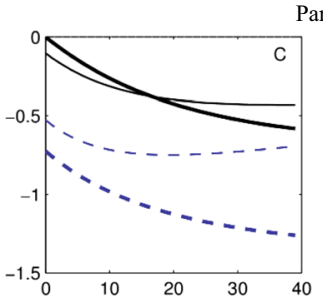

Panel C. Idiosyncratic shock to the $(\boldsymbol{L}, \boldsymbol{R})$ region.
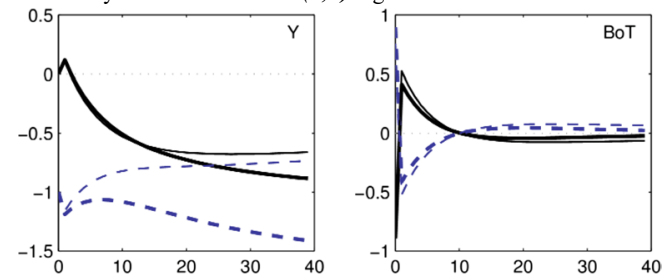

- Region $(C, R) \alpha_{G}=$ high; - - - Region $(L, R) \alpha_{G}=$ high; — Region $(C, R) \alpha_{G}=$ very low; - - - Region $(L, R) \alpha_{G}=$ very low

Fig. 6 Responses of output, consumption, and investment to the $-1 \%$ productivity shocks under alternative assumptions about the productivity of public goods. The $U[(C, R),(L, R)]$ fiscal union is considered. The vertical axis measures percentage deviations of the variables from their respective steady states with the exception of the balance of trade measured relative to the steady-state output. The technology process with spillovers is adopted. The horizontal axis measures periods after the shock

the Region 2 household. Therefore, conditional on low public good productivity, the household in the latter region enjoys a higher utility level.

\section{Welfare and risk sharing}

This section explores the welfare and interregional consumption risk-sharing properties of two types of fiscal unions: (i) a union in which regional governments choose the type of taxes to impose on their constituents, and (ii) a union in which policymakers specify the public borrowing limits. To designate specific unions, we shall adopt the following notation: $U[(X, Y),(X, Y)]$, where the parentheses refer to the two regions, $X=\{C, L\}$, according to whether the region taxes 
Table 4 Lifetime welfare dynamics in response to $1 \%$ decline in aggregate productivity

\begin{tabular}{|c|c|c|c|c|c|c|c|c|}
\hline \multirow{2}{*}{$\begin{array}{l}\text { Fiscal union } \\
\text { A. Higher persistence; no regional spillover }\end{array}$} & \multicolumn{4}{|c|}{$\begin{array}{l}\text { Region 1: }[(\mathrm{C}, \mathrm{R})] \\
\text { Region 2: }[(\mathrm{L}, \mathrm{R})] \\
\text { Asymmetric tax system }\end{array}$} & \multicolumn{4}{|c|}{$\begin{array}{l}\text { Region 1: }[(\mathrm{C}, \mathrm{R})] \\
\text { Region 2: }[(\mathrm{C}, \mathrm{F})] \text { Asym- } \\
\text { metric borrowing limits }\end{array}$} \\
\hline & & & & & & & & \\
\hline \multirow{2}{*}{ Elasticity of output with respect to $\alpha_{\mathrm{G}}$} & V low & Low & Med & High & V low & Low & Med & High \\
\hline & 0.05 & 0.10 & 0.20 & 0.30 & 0.05 & 0.10 & 0.20 & 0.30 \\
\hline Loss of lifetime welfare in Region 1 (\%) & 1.05 & 1.10 & 1.22 & 1.37 & 1.07 & 1.15 & 1.35 & 1.63 \\
\hline Loss of lifetime welfare in Region $2(\%)$ & 1.04 & 1.13 & 1.34 & 1.64 & 1.08 & 1.07 & 1.02 & 0.96 \\
\hline Welfare loss ratio of Region 1 to Region 2 & 1.004 & 0.98 & 0.91 & 0.83 & 0.99 & 1.07 & 1.32 & 1.70 \\
\hline Fiscal union & \multicolumn{4}{|c|}{$\begin{array}{l}\text { Region 1: }[(\mathrm{C}, \mathrm{R})] \\
\text { Region 2: }[(\mathrm{L}, \mathrm{R})] \\
\text { Asymmetric tax system }\end{array}$} & \multicolumn{4}{|c|}{$\begin{array}{l}\text { Region } 1:[(\mathrm{C}, \mathrm{R})] \\
\text { Region 2: }[(\mathrm{C}, \mathrm{F})] \text { Asym- } \\
\text { metric borrowing limits }\end{array}$} \\
\hline \multicolumn{9}{|l|}{ B. Lower persistence with regional spillovers } \\
\hline \multirow[t]{2}{*}{ Elasticity of output with respect to $\alpha_{\mathrm{G}}$} & V low & Low & Med & High & V low & Low & Med & High \\
\hline & 0.05 & 0.10 & 0.20 & 0.30 & 0.05 & 0.10 & 0.20 & 0.30 \\
\hline Loss of lifetime welfare in Region $1(\%)$ & 0.76 & 0.80 & 0.88 & 0.98 & 0.77 & 0.83 & 0.98 & 1.18 \\
\hline Loss of lifetime welfare in Region $2(\%)$ & 0.75 & 0.82 & 0.98 & 1.21 & 0.78 & 0.77 & 0.74 & 0.69 \\
\hline Welfare loss ratio of Region 1 to Region 2 & 1.01 & 0.97 & 0.90 & 1.81 & 0.99 & 1.08 & 1.32 & 1.71 \\
\hline
\end{tabular}

Entries of this table are calculated using consumption scale factors and have interpretation of compensating variation measured in terms of private consumption units

consumption or labor income, and $Y=\{R, F\}$, depending upon whether the region is subject to a rigid or flexible borrowing limit.

Section 6.1 considers unions in which regional governments adopt asymmetric fiscal policies. We begin with the benchmark $U[(C, R),(L, R)]$ in which the government of Region 1 taxes consumption, while the government of Region 2 taxes labor income, and neither government can issue debt. We compare this to $U[(C$, $R),(C, F)]$ in which both regional governments finance their expenditures with a consumption tax, but the government of Region 1 is subject to a rigid balanced budget, while the government of Region 2 has the flexibility to borrow to stabilize the economy after the realization of an adverse shock.

Section 6.2, extends our analysis of the first type of fiscal union (in which both regional governments are constrained by rigid borrowing limits) by introducing two additional, symmetric tax regimes. These are $U[(C, R),(C, R)]$, where both Regions 1 and 2 tax consumption, and $U[(L, R),(L, R)]$ where both regions tax labor income. Section 6.3 applies the same approach to the second type of fiscal union (in which policymakers design public borrowing limits conditional on collecting the consumption tax). Thus, in $U[(C, F),(C, F)]$ both regional governments are able to borrow in the event of an adverse shock, while in $U[(C, R),(C$, $R)$ ], both regions are subject to a rigid borrowing constraint. Section 6.4 contrasts the implications for union welfare and risk-sharing of: (i) regional tax choices and (ii) public borrowing limit choices made by the regional authorities. 


\section{1 $U[(C, R),(L, R)]$ and $U[(C, R),(C, F)]$ fiscal unions}

We compare the welfare and consumption risk-sharing characteristics of these two benchmark asymmetric fiscal unions, following one-time, aggregate and idiosyncratic, $1 \%$ adverse productivity shocks. In each case we first abstract from technology spillovers across the regions, and then briefly discuss the welfare consequences of the introduction of technology spillovers.

\subsubsection{An aggregate economy-wide $1 \%$ decline in productivity}

The long-run regional welfare costs for this case are summarized in Table 4 . We begin by considering the baseline case of medium public good productivity $\left(\alpha_{\mathrm{G}}=0.20\right)$ for $U[(C, R),(L, R)]$ with no technology spillovers. Following the realization of an aggregate technology shock, the consumption paths of the two regions diverge (left-hand side of Panel A, Table 4). The welfare cost of the shock for Region 1 equals $1.22 \%$ of lifetime consumption, whereas the cost for Region 2 is larger and equals $1.34 \%$ of lifetime consumption. According to this metric, the ratio of the welfare loss in Region 1 to Region 2 is 0.91 ; taxing consumption is clearly superior to taxing labor income.

From the right hand side of this panel we see that if instead of taxing labor income, Region 2 also taxed consumption, coupled with allowing a flexible borrowing limit, the relative welfare costs to the two regions would be reversed. The welfare cost to Region 2 would now be reduced to $1.02 \%$ of lifetime consumption, while that of Region 1 would be increased to $1.35 \%$. Taken together, the total cost to the two regions would be reduced from 2.56 to $2.37 \%$.

As the productivity of public capital increases, risk-sharing deteriorates. The representative household in the consumption-taxing region withstands the economy-wide adverse productivity decline better than does the household in the labor income-taxing region. The interregional consumption differential widens, and for $\alpha_{\mathrm{G}}=0.30$, the welfare loss ratio decreases to 0.83 (Panel A, Table 4). However, if the productivity of public capital declines to a very low level $\left(\alpha_{\mathrm{G}}=0.05\right)$, the interregional consumption differential shrinks to a one-hundredth of $1 \%$ of lifetime consumption and the Region 1-Region 2 welfare loss ratio equals 1.004. That is, the region that taxes consumption now performs worse than does the region that taxes labor income, albeit only marginally.

The same general pattern applies to the $U[(C, R),(C, F)]$ union. As long as $\alpha_{\mathrm{G}} \geq 0.10$, the flexible region, by providing a larger quantity of public capital, outperforms the rigid region in terms of welfare costs to its representative household. However, as for the $U[(C, R),(L, R)]$ union, for extremely low public good productivity, the results are reversed and the fiscal policies of the rigid regions yield higher welfare, although the welfare improvement is negligible (the ratio of the welfare loss amounts to 1.01).

The effect of technology spillovers across regions is to moderate the welfare costs to both regions following the aggregate productivity shock. Thus, in the benchmark case of $U[(C, R),(L, R)]$, the welfare cost to Region 1 is reduced from 1.22 to $0.88 \%$, while that of Region 2 is reduced from 1.34 to $0.98 \%$. The welfare losses for both 
regions are reduced by approximately the same proportion of about $27 \%$. The same applies to the case of asymmetric borrowing limits, $U[(C, R),(C, F)]$ where the spillovers reduce the welfare costs of Region 1 from 1.35 to $0.98 \%$ and those of Region 2 from 1.02 to $0.74 \%$. The pattern of responses to the varying degrees of productivity of public capital, $\alpha_{\mathrm{G}}$, remains unaffected.

\subsubsection{Idiosyncratic (Regional) $1 \%$ decline in productivity}

Table 5 reports the welfare costs of idiosyncratic declines in productivity, with Panel A describing when they occur in $U[(C, R),(L, R)]$ (Region 1 ) and Panel B referring to $U[(C, R),(C, F)]$ (Region 2). The table also distinguishes between the presence of, and absence of, regional spillovers (Table 6).

In the absence of technology spillovers across regions, an adverse productivity shock in one region has only a limited impact on the other region. In fact, only the region directly affected by the shock experiences an economic contraction, amplified by the outward migration of productive resources, while the other region actually benefits from the inward shift of resources and approaches its steady state from above. Regardless of whether the negative idiosyncratic productivity disturbance occurs in the consumption tax-collecting region, or in the labor income-taxing region, their welfare losses are almost identical $(1.71 \%$ and $1.73 \%$ of lifetime consumption for $\alpha_{\mathrm{G}}=0.20$, correspondingly). In either case, the other region gains $0.40 \%$ in lifetime consumption.

In most cases, the welfare consequences of a regional-specific productivity shock are sensitive to the productive elasticity of public capital, $\alpha_{\mathrm{G}}$. The interregional consumption gap widens as $\alpha_{\mathrm{G}}$ increases, and narrows as it declines. In the case where the productivity decline occurs in Region 1 (the consumption-taxing region), the (differential) welfare costs to both regions are approximately the same, whether Region 2 adopts a $(L, R)$ or a $(C, F)$ fiscal regime. In either case, Region 2 receives the identical quantity of resources from the directly impacted Region 1, enjoying similar welfare improvement. In both cases, public capital is provided at the preshock steady-state level (dependent on $\alpha_{\mathrm{G}}$ ) without relying on borrowing to do so.

The one exception to this scenario is if the idiosyncratic decline in productivity occurs in Region 2 , when it adopts the $(C, F)$ fiscal regime. ${ }^{26}$ In this case the welfare consequences for both regions are independent of the productivity of public capital $\alpha_{\mathrm{G}}$. In all cases, Region 2 experiences a welfare loss of $1.40 \%$, while welfare in Region 1 increases by $0.30 \%$. This reflects the fact that because the flexible borrowing limit allows the $(C, F)$ region to fully compensate for the loss of tax revenue after realization of an idiosyncratic shock, it provides productive public goods at the

\footnotetext{
26 The regional welfare implications in the case where Region 2 operates under the $(L, R)$ fiscal regime are virtually the mirror image of the case where the productivity decline occurs in Region 1.
} 
Table 5 Lifetime welfare dynamics in response to $1 \%$ decline in productivity in Region 1

\begin{tabular}{|c|c|c|c|c|c|c|c|c|}
\hline \multirow{4}{*}{$\begin{array}{l}\text { Fiscal union } \\
\text { Higher persistence; no regional spillov }\end{array}$} & \multicolumn{4}{|c|}{$\begin{array}{l}\text { Region 1: }[(\mathrm{C}, \mathrm{R})] \\
\text { Region 2: }[(\mathrm{L}, \mathrm{R})] \\
\text { Asymmetric tax system }\end{array}$} & \multicolumn{4}{|c|}{$\begin{array}{l}\text { Region 1: }[(\mathrm{C}, \mathrm{R})] \\
\text { Region } 2:[(\mathrm{C}, \mathrm{F})] \\
\text { Asymmetric borrowing limits }\end{array}$} \\
\hline & \multicolumn{8}{|l|}{ ers } \\
\hline & V low & Low & Med & High & V low & Low & Med & High \\
\hline & 0.05 & 0.10 & 0.20 & 0.30 & 0.05 & 0.10 & 0.20 & 0.30 \\
\hline $\begin{array}{l}\text { Loss of lifetime welfare in Region } \\
1(\%)\end{array}$ & 1.36 & 1.46 & 1.71 & 2.07 & 1.36 & 1.46 & 1.71 & 2.07 \\
\hline $\begin{array}{l}\text { Loss of lifetime welfare in Region } \\
2(\%)\end{array}$ & -0.32 & -0.34 & -0.40 & -0.48 & -0.32 & -0.34 & -0.40 & -0.48 \\
\hline Fiscal union & \multicolumn{4}{|c|}{$\begin{array}{l}\text { Region 1: }[(\mathrm{C}, \mathrm{R})] \\
\text { Region 2: }[(\mathrm{L}, \mathrm{R})] \\
\text { Asymmetric tax system }\end{array}$} & \multicolumn{4}{|c|}{$\begin{array}{l}\text { Region 1: }[(\mathrm{C}, \mathrm{R})] \\
\text { Region 2: }[(\mathrm{C}, \mathrm{F})] \text { Asym- } \\
\text { metric borrowing limits }\end{array}$} \\
\hline \multicolumn{9}{|l|}{ Lower persistence with regional spillovers } \\
\hline \multirow[t]{2}{*}{ Elasticity of output with respect to $\alpha_{\mathrm{G}}$} & V low & Low & Med & High & V low & Low & Med & High \\
\hline & 0.05 & 0.10 & 0.20 & 0.30 & 0.05 & 0.10 & 0.20 & 0.30 \\
\hline $\begin{array}{l}\text { Loss of lifetime welfare in Region } \\
1(\%)\end{array}$ & 0.53 & 0.57 & 0.65 & 0.75 & 0.54 & 0.58 & 0.68 & 0.82 \\
\hline $\begin{array}{l}\text { Loss of lifetime welfare in Region } \\
2(\%)\end{array}$ & 0.22 & 0.24 & 0.29 & 0.35 & 0.23 & 0.22 & 0.20 & 0.17 \\
\hline
\end{tabular}

Table 6 Lifetime welfare dynamics in response to $1 \%$ decline in productivity in Region 2

\begin{tabular}{|c|c|c|c|c|c|c|c|c|}
\hline \multirow{2}{*}{$\begin{array}{l}\text { Fiscal union } \\
\text { Higher persistence; no regional spillove }\end{array}$} & \multicolumn{4}{|c|}{$\begin{array}{l}\text { Region 1: }[(\mathrm{C}, \mathrm{R})] \\
\text { Region 2: }[(\mathrm{L}, \mathrm{R})] \\
\text { Asymmetric tax system }\end{array}$} & \multicolumn{4}{|c|}{$\begin{array}{l}\text { Region 1: }[(\mathrm{C}, \mathrm{R})] \\
\text { Region 2: }[(\mathrm{C}, \mathrm{F})] \\
\text { Asymmetric borrowing limits }\end{array}$} \\
\hline & & & & & & & & \\
\hline \multirow[t]{2}{*}{ Elasticity of output with respect to $\alpha_{\mathrm{G}}$} & V low & Low & Med & High & V low & Low & Med & High \\
\hline & 0.05 & 0.10 & 0.20 & 0.30 & 0.05 & 0.10 & 0.20 & 0.30 \\
\hline $\begin{array}{l}\text { Loss of lifetime welfare in Region } \\
1(\%)\end{array}$ & -0.32 & -0.34 & -0.40 & -0.49 & -0.30 & -0.30 & -0.30 & -0.30 \\
\hline $\begin{array}{l}\text { Loss of lifetime welfare in Region } \\
2(\%)\end{array}$ & 1.35 & 1.46 & 1.73 & 2.10 & 1.40 & 1.40 & 1.40 & 1.40 \\
\hline Fiscal union & \multicolumn{4}{|c|}{$\begin{array}{l}\text { Region } 1:[(\mathrm{C}, \mathrm{R})] \\
\text { Region } 2:[(\mathrm{L}, \mathrm{R})] \\
\text { Asymmetric tax system }\end{array}$} & \multicolumn{4}{|c|}{$\begin{array}{l}\text { Region 1: }[(\mathrm{C}, \mathrm{R})] \\
\text { Region 2: }[(\mathrm{C}, \mathrm{F})] \text { Asym- } \\
\text { metric borrowing limits }\end{array}$} \\
\hline \multicolumn{9}{|l|}{ Lower persistence with regional spillovers } \\
\hline \multirow[t]{2}{*}{ Elasticity of output with respect to $\alpha_{\mathrm{G}}$} & V low & Low & Med & High & V low & Low & Med & High \\
\hline & 0.05 & 0.10 & 0.20 & 0.30 & 0.05 & 0.10 & 0.20 & 0.30 \\
\hline $\begin{array}{l}\text { Loss of lifetime welfare in Region } \\
1(\%)\end{array}$ & 0.23 & 0.23 & 0.24 & 0.23 & 0.23 & 0.25 & 0.30 & 0.36 \\
\hline $\begin{array}{l}\text { Loss of lifetime welfare in Region } \\
2(\%)\end{array}$ & 0.53 & 0.58 & 0.69 & 0.86 & 0.55 & 0.55 & 0.54 & 0.52 \\
\hline
\end{tabular}

Entries of this table are calculated using consumption scale factors and have interpretation of compensating variation measured in terms of private consumption units 


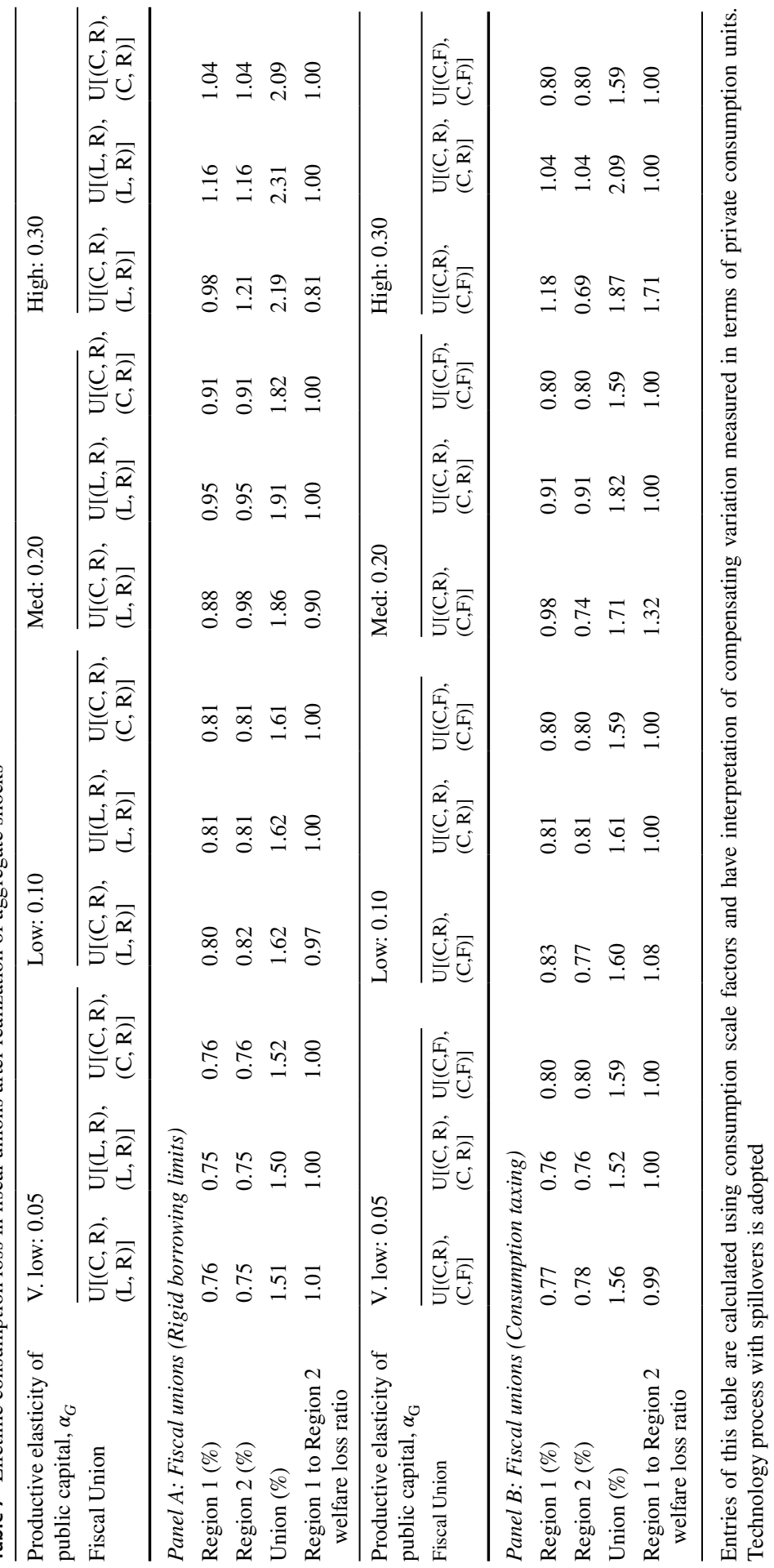


pre-shock level. The welfare gain experienced by Region 1, as in other cases, is due to the shift of resources. ${ }^{27}$

In the scenarios where the regional idiosyncratic shocks involve technology spillovers, they propagate adverse shocks across the entire union, so that both members of the union enter a recession and approach their steady states from below. Thus, spillovers improve consumption risk-sharing, and mitigate interregional welfare differences.

\subsection{Tax system choice}

In this section, we broaden the choice of tax systems constrained initially by the requirement that each region is subject to a rigid budget constraint. ${ }^{28} \mathrm{We}$ first focus on the specified baseline degree of public capital productivity, $\alpha_{\mathrm{G}}=0.20$, and then allow for variations in this key parameter. Since the welfare and risk sharing performance of fiscal unions after the realization of aggregate shocks is almost identical, regardless of the technology process specification, we report estimates for the specification with spillovers unless noted otherwise.

As demonstrated above, the realization of an aggregate productivity shock in a fiscal union with asymmetric tax systems generates asymmetric allocations. This asymmetry, in an environment of regional capital mobility, is amplified by a shift of resources to the region with higher marginal productivity. Focusing on the baseline parameterization $\alpha_{\mathrm{G}}=0.20$ in Panel A of Table 7, the $U[(C, R),(L, R)]$ benchmark fiscal union is associated with an economy-wide welfare loss of $1.86 \%$ of lifetime consumption. Of this loss, $0.88 \%$ is borne by Region 1 and $0.98 \%$ by Region 2 , implying a Region 1 to Region 2 welfare loss of $0.90 \%$ (Table 8).

Suppose now that both regional governments adopt a labor income tax. In this case, the lifetime welfare loss of Region 2 would decrease by $0.03 \%$ of lifetime consumption, while the loss of Region 1 would increase by $0.07 \%$. Although risk-sharing would be perfect in this union (the interregional consumption ratio becomes 1), the net effect of such a tax system reform would be adverse from the overall union standpoint, and would increase the combined welfare loss by $0.05 \%$ of aggregate lifetime consumption.

If, on the other hand, both regions tax consumption, Region 1's lifetime welfare loss following an aggregate shock increases, but only by a modest $0.03 \%$ of lifetime consumption. At the same time, the welfare gain of Region 2 amounts to $0.07 \%$ of lifetime consumption. Therefore, if both regions tax consumption, this both reduces the combined union welfare losses and achieves perfect risk-sharing. The latter is

\footnotetext{
27 This finding illustrates a key point this paper makes, namely that the borrowing limit choice is more consequential for welfare and risk sharing than is the design of the tax system. This point is supported by the lower rows of Table 5, where welfare losses are identical for unions that impose any combination of taxes as long as they adopt Flexible borrowing limits.

28 While we appreciate the salience of strategic interaction, we abstract from it for the sake of providing an unobstructed analysis of macroeconomic mechanisms of shock transmission and risk sharing in the fiscal union. In this context, we use the terms 'the choice of tax system or public borrowing rule' or 'union public finance system design' in a narrow sense.
} 


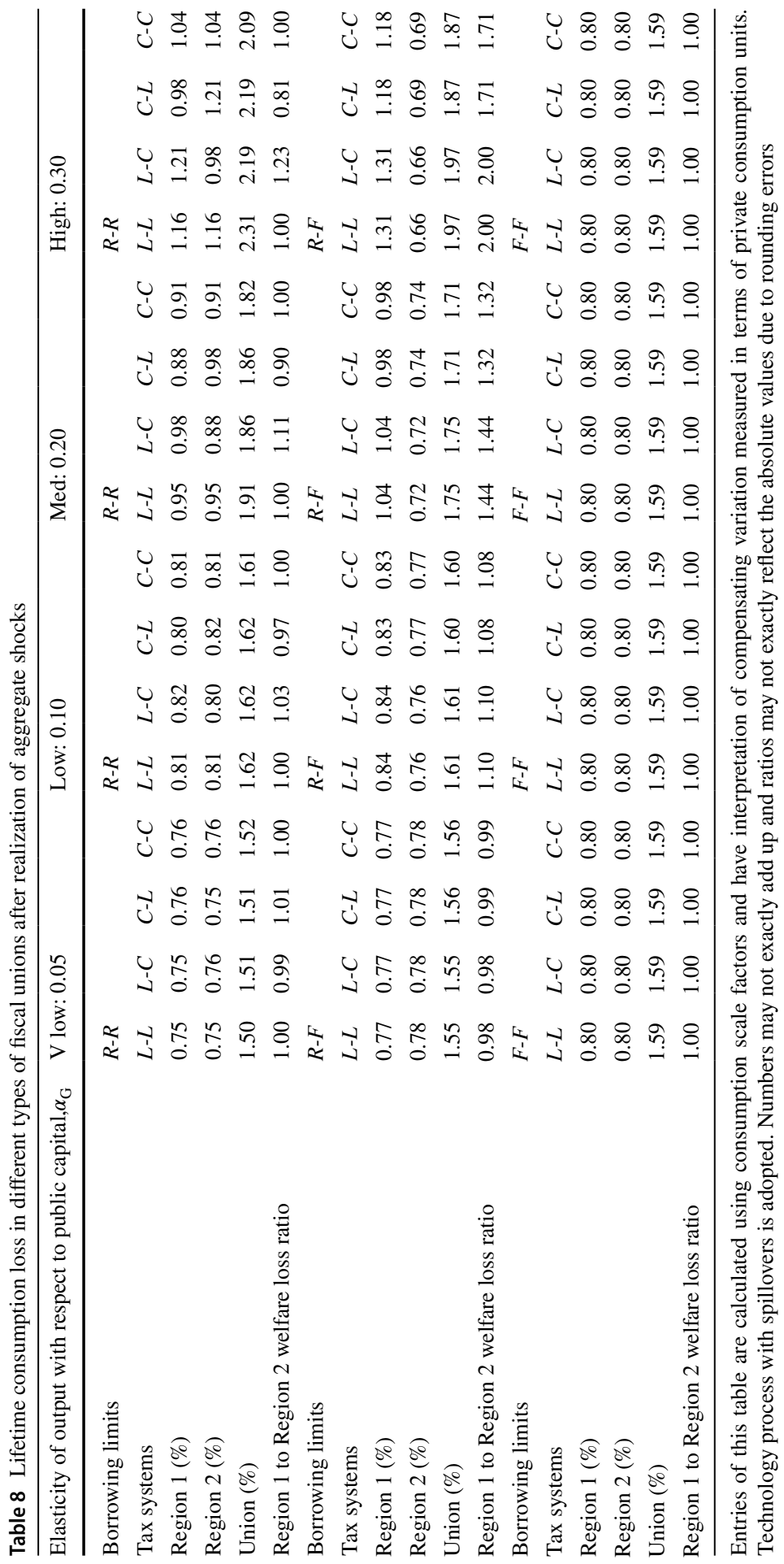


due to the symmetric provision of the productive public goods by the regional governments, which does not result in the interregional marginal productivity differential and, hence, does not incentivize the shift of resources. The decline in the welfare cost of business fluctuations is due to higher consumption tax revenues collected on impact and in the wake of the shock realization, relative to tax revenues of a region with a labor income tax system in place, which translates in a steadier provision of productive public goods in the $U[(C, R),(C, R)]$ union.

Panel A of Table 7 indicates how the welfare costs of business cycles, where regions are subject to borrowing constraints, are affected as $\alpha_{G}$ increases from 0.05 to 0.30 . We see that the welfare cost of business cycles in the benchmark $U[(C, R)$, $(C, F)]$ union increases with the productivity of public goods and reaches $2.19 \%$ of lifetime consumption public good for $\alpha_{\mathrm{G}}=0.30$. In this case, the interregional consumption differential amounts to $0.23 \%$ of lifetime consumption and interregional welfare loss ratio equals 0.81 . If both regional governments tax labor income, the interregional consumption differential is reduced, but the welfare cost of productivity shocks would increase to $2.31 \%$. This comparison illustrates the fact that the under-provision of public capital becomes costlier as its productivity increases. By contrast, substituting the labor income tax in Region 2 with the consumption tax improves the union welfare by 0.10 . This improvement is due to the fact that the marginal benefit of an ample supply of public capital increases with its productivity.

As the public good productivity declines, several observations can be made. First, the cost of the public good under-provision diminishes, as measured by the reduced welfare cost of the shocks, and smaller interregional consumption differentials. Second, if the productivity of public capital is $\alpha_{\mathrm{G}}=0.10$, which is low, but certainly within the empirically plausible range as reported by Bom and Ligthart (2014), the welfare losses stemming from the aggregate productivity decline. In addition, the differences in the welfare losses both between regions and for alternative regional taxation schemes are small, and essentially negligible. Finally, if the productivity of public capital is reduced further to $\alpha_{\mathrm{G}}=0.05$, taxing labor income is superior to taxing consumption. But again the difference is negligible and one can argue that if the productivity of public capital is sufficiently low, and regional governments are constrained in their ability to borrow, the choice of taxation by regional governments is unimportant.

The above qualitative conclusions carry over to the specification of no technology spillovers. By removing interregional spillovers, the established effects of the tax systems are amplified by up to $0.03 \%$ of lifetime consumption. ${ }^{29}$ Benefits of harmonizing the tax structure across regions are higher. In other words, the cost of maintaining the status quo asymmetric $U[(C, R),(C, F)]$ tax system is higher in the absence of spillovers, including when the productivity of public capital is low.

${ }^{29}$ Estimates in the absence of regional spillovers are available on request. 


\subsection{Public borrowing limit choice}

Asymmetric public borrowing limits also deteriorate consumption risk sharing. To see this, we focus on the benchmark $U[(C, R),(C, F)]$ fiscal union in Table 8, Panel B. There it is seen that for the benchmark productivity of public capital $\alpha_{\mathrm{G}}=0.20$, Region 1 experiences a welfare loss of $0.98 \%$, Region 2 suffers a smaller welfare loss of $0.74 \%$, with the total union welfare loss of $1.71 \%$. Harmonization of regional public borrowing limits in the union yields perfect risk sharing in the presence of an aggregate productivity shock.

As long as the productivity of public capital $\alpha_{G}$ exceeds 0.05 , minimization of the union welfare loss is achieved when both regions adopt Flexible borrowing limits. However, in the extreme case of very low public good productivity, the welfare loss is minimized if both regional governments refrain from borrowing. ${ }^{30}$

As for the benchmark asymmetric tax union, $U[(C, R),(L, R)]$, discussed in Sect. 6.2, the welfare gains of the welfare-improving public finance reforms in the $U[(C, R),(C, F)]$ union are modest for very low, or low, public good productivity. But as the productivity of public capital increases, the benefits of such reforms increase as well. For the baseline productivity of public capital, $\alpha_{\mathrm{G}}=0.20$, the welfare cost of an aggregate shock in the symmetric $U[(C, F),(C, F)]$ fiscal union falls to $1.59 \%$ of lifetime consumption from $1.71 \%$ in the asymmetric $U[(C, R),(L, R)]$ fiscal union. The decline is from 1.87 to $1.59 \%$ for $\alpha_{\mathrm{G}}=0.30$.

\subsection{Tax system versus public borrowing limit choice}

Table 8 summarizes the welfare losses for the complete array of potential fiscal unions following a $1 \%$ decline in aggregate productivity, in the case where regional spillovers are assumed to occur. ${ }^{31}$ The pairing $R$ - $R$ etc. characterizes regional borrowing limits, and $C$ - $L$ etc. describes their form of taxation. In the case that both regions are subject to the same borrowing restriction, but impose different tax systems, the impacts are symmetric. Thus, for example, if both regions are subject to a flexible limit the regional allocations of the welfare costs of the $L-C$ and $C-L$ tax systems are simply reversed. This is a consequence of the two regions being structurally identical.

The upper panel of Table 8 reports the performance of the union in which both regional governments are unable to borrow. This effectively replicates Panel A of Table 7. As discussed above in Sect. 6.2, provided public capital is sufficiently productive $\left(\alpha_{\mathrm{G}} \geq 0.10\right)$ the best outcome in the union with constraints on public borrowing is achieved when both regions tax consumption. In that case is not only fiscal union welfare loss minimized, but it also is evenly split between its members.

\footnotetext{
${ }^{30}$ Detailed analysis of the shock transmission mechanism in the $\boldsymbol{U}[(\boldsymbol{C}, \boldsymbol{R}),(\boldsymbol{L}, \boldsymbol{R})]$ union is presented in Dashkeev and Turnovsky (2018).

31 Table 9 reports the welfare costs for fiscal unions in which there are no technological spillovers across the regions.
} 
However, if the productivity of public capital is extremely low, labor income-taxation is marginally superior.

The central panel of Table 7 reports welfare costs for the "mixed" union, where the two regions are subject to different borrowing restrictions. In such a union, the choice of tax system by the region that adopts the Flexible borrowing limit does not affect its welfare performance. Its government is doing everything to maximize the flow of productive public goods by removing the constraints on public borrowing. At the same time, the tax regime choice of the other union member does affect the performance of the Flexible region, though to a limited degree. This result hinges on the shift of resources from the Rigid to Flexible region, and the magnitude depends on the tax structure adopted by the authorities of the Rigid region. For instance, for $\alpha_{\mathrm{G}}=0.20$, if the Rigid region chooses to tax consumption, the Flexible region's cost of business cycles is $0.74 \%$ of lifetime consumption. If, instead, the Rigid region taxes labor income, the Flexible region's loss decreases to $0.72 \%$ of lifetime consumption. This is because the interregional marginal productivity differential tilted in favor of the Flexible region is now higher, and the corresponding shift of resources is greater. Risk-sharing is imperfect in the $R-F$ union, and the ratio of regional losses ranges between 1.44 and 1.32, depending on the tax system adopted by the Rigid region. But the ratio of the regional welfare losses are quite sensitive to the productivity of public capital, $\alpha_{\mathrm{G}}$.

The lower panel of Table 8 suggests that the union-wide adoption of Flexible borrowing limits minimizes the costs of business fluctuations. Once constraints on public borrowing are removed, in other words, the uninterrupted provision of public investment is ensured. The choice of tax system by regional governments becomes irrelevant in the sense that it does not affect the welfare costs of business cycles, which are equal to $0.80 \%$ of lifetime consumption for each region. Additionally, the $F-F$ union is the only one in which perfect risk sharing is achieved after the occurrence of the aggregate productivity shock, regardless of the tax system choice.

The findings summarized in Table 8 clearly suggest that the nature of the public borrowing constraint imposed on the regional government is substantially more important than is their choice of tax systems insofar as risk-sharing and the welfare costs of business cycles are concerned. In the case of interregional risk-sharing, the asymmetric public borrowing limit arrangement is more detrimental for risk sharing than is the asymmetric tax system. With respect to the welfare cost-of-business cycles, for asymmetric fiscal unions, the welfare-maximizing borrowing limit design can reduce the cost of business cycles more than can the welfare-maximizing tax system design.

As the productivity of public goods declines from high to low, the interregional differences ameliorate, the shift of resources between the regions decreases, and risk-sharing improves (in those asymmetric cases when it was not perfect). When the productivity of public investment becomes extremely low, the results are reversed. As discussed earlier, the withdrawal of resources from private use is not justified when their public use is just marginally productive. In these circumstances, the pattern established above breaks, and the welfare costs of business cycles are minimized in the $U[(C, R),(C, R)]$ fiscal union. Notice that, conditional on very low public good productivity, the maximum improvement of the fiscal union welfare is 
just $0.09 \%$ of lifetime consumption. This would occur if the federal system moves to $U[(C, R),(C, R)]$ fiscal union from a union in which both regions have fully flexible borrowing limits. Therefore, the productivity of public goods is the key parameter that determines the welfare-maximizing design of fiscal unions.

\section{Conclusions}

In this paper, we have compared the implications of tax system and public borrowing limit asymmetries for the welfare cost of business cycles and interregional consumption risk sharing in a fiscal union. In this process the welfare-improving and risk-sharing-improving designs of the regional tax systems and borrowing limits have been identified. We have approached this issue through the lens of a two-region DSGE model that is augmented with the public-sector features of a federal state.

This study clearly demonstrates that the choice of public borrowing limits is more consequential than is the choice of a tax regime for the union welfare. It also serves as an argument for the harmonization of fiscal policies adopted in the fiscal union, as it would internalize fiscal externalities and improve consumption risk-sharing across the union regions.

The key parameter that determines the merits of alternative regional tax systems and possible limits to public borrowing in the fiscal union is the productivity of public good. Other aspects of the economy, such as the type of technology process, or the nature of the productivity shock (aggregate or idiosyncratic), do not affect the union public finance system design significantly. Our simulations suggest that if the productivity of public capital lies within the range of plausible empirical estimates, allowing both regions to have flexible borrowing limits and to choose whatever tax system they wish will minimize the overall welfare costs of business fluctuations. However, for very low productivity of public capital, the welfare-maximizing regional public finance reforms that would prohibit public borrowing and impose the labor income tax can produce limited benefits.

In reaching these conclusions, we must bear in mind that we have made (at least) two crucial assumptions, namely that the two regions are structurally identical and that labor is both inelastically supplied and immobile. While these assumptions serve as a natural starting point, in reality regions are typically diverse, while labor will not only respond to tax rates within their region, but may migrate to regions which they view as having a favorable tax structure. Clearly extending this framework to deal with these important aspects is a natural next step. ${ }^{32}$

\footnotetext{
32 We also assume frictionless labor and capital markets. The introduction of frictions into either or both of the labor and the capital markets would inhibit adjustments of the macroeconomic variables following the realization of the shock and, therefore, would amplify the welfare costs of business fluctuations and deteriorate the interregional risk-sharing. Similarly, relaxing the flexible price assumption and increasing the degree of price stickiness would magnify the welfare cost and further worsen risk-sharing. Because we assume away these frictions, with the exception of the prohibitively high interregional labor mobility friction, our results characterize the lower bound of the welfare cost of business cycles in a fiscal union with immobile labor.
} 
As a final post script, we note that while our analysis has focused on the merits of the fiscal union from the perspective of dealing with productivity shocks, the framework we have developed can readily be adapted to focus on other types of shocks, such as countries are currently enduring as a consequence of the COVID-19 pandemic. This is a very topical issue, especially given the ongoing debate between the Federal government and State governors, and one on which this type of analysis can shed light.

\section{Appendix 1: Net regional asset accumulation}

This appendix derives the expression for net regional asset accumulation for Region 1 .

Aggregate accounting implies the following laws of motion for net regional assets in Region 1 and Region 2:

$$
\begin{gathered}
B_{t+1}-\left(1+R_{\mathrm{PRI}, \mathrm{t}}\right) B_{\mathrm{t}}=R_{\mathrm{t}} K_{\mathrm{t}}+W_{\mathrm{t}} \bar{L}-C_{\mathrm{t}}-I_{\mathrm{t}}-I_{\mathrm{RG}, \mathrm{t}}-\frac{1}{2} C_{\mathrm{G}}, \\
B_{t+1}^{*}-\left(1+R_{\mathrm{PRI}, \mathrm{t}}\right) B_{\mathrm{t}}^{*}=R_{\mathrm{t}}^{*} K_{\mathrm{t}}^{*}+W_{\mathrm{t}}^{*} \overline{L^{*}}-C_{\mathrm{t}}^{*}-I_{\mathrm{t}}^{*}-I_{\mathrm{RG}}^{*}-\frac{1}{2} C_{\mathrm{G}} .
\end{gathered}
$$

The right-hand side of each of the laws of motion is a regional equivalent of the System of National Accounts' definition of national savings for a sovereign state: national income less domestic absorption. If the regional savings are positive (negative), the region runs a trade surplus (deficit) and holds a positive (negative) net regional asset position.

Subtracting the latter equation from the former yields:

$$
\begin{aligned}
B_{t+1}-\left(1+R_{\mathrm{PRI}, \mathrm{t}}\right) B_{\mathrm{t}}= & \frac{1}{2}\left(R_{\mathrm{t}} K_{\mathrm{t}}-R_{\mathrm{t}}^{*} K_{\mathrm{t}}^{*}\right)+\frac{1}{2}\left(W_{\mathrm{t}} \bar{L}-W_{\mathrm{t}}^{*} \overline{L^{*}}\right) \\
& -\frac{1}{2}\left(C_{\mathrm{t}}-C_{\mathrm{t}}^{*}\right)-\frac{1}{2}\left(I_{\mathrm{t}}-I_{\mathrm{t}}^{*}\right)-\frac{1}{2}\left(I_{\mathrm{RG}, \mathrm{t}}-I_{\mathrm{RG}}^{*}\right) .
\end{aligned}
$$

Using the fact that private bonds are in zero net supply, $B_{\mathrm{t}}+B_{\mathrm{t}}{ }^{*}=0$, and due to the Federal government apportioning procurement of the consumption public good equally between the regions, one can rewrite (23) as

$$
\begin{aligned}
B_{t+1}-\left(1+R_{\mathrm{PRI}, \mathrm{t}}\right) B_{\mathrm{t}} & =\frac{1}{2}\left(R_{\mathrm{t}} K_{\mathrm{t}}-R_{\mathrm{t}}^{*} K_{\mathrm{t}}^{*}\right)+\frac{1}{2}\left(W_{\mathrm{t}} \bar{L}-W_{\mathrm{t}}^{*} \bar{L}^{*}\right) \\
& -\frac{1}{2}\left(C_{\mathrm{t}}-C_{\mathrm{t}}^{*}\right)-\frac{1}{2}\left(I_{\mathrm{t}}-I_{\mathrm{t}}^{*}\right)-\frac{1}{2}\left(I_{\mathrm{RG}, \mathrm{t}}-I_{\mathrm{RG}}^{*}\right) .
\end{aligned}
$$

This equation relates the Region 1 net regional asset accumulation to the interest income and differentials between the two regions' capital income, labor income, private absorption, and public absorption. 


\section{Appendix 2 Summary of the model equilibrium conditions}

\begin{tabular}{|c|c|}
\hline Rate of return on labor & $\begin{array}{l}W_{\mathrm{t}}=(1-\alpha) Y_{\mathrm{t}} / \bar{L} \\
W_{\mathrm{t}}^{*}=(1-\alpha) Y_{\mathrm{t}}^{*} / \overline{L^{*}}\end{array}$ \\
\hline Rate of return on capital & $\begin{array}{l}R_{\mathrm{t}}=\alpha Y_{\mathrm{t}} / K_{\mathrm{t}} \\
R_{\mathrm{t}}^{*}=\alpha Y_{\mathrm{t}}^{*} / K_{\mathrm{t}}^{*}\end{array}$ \\
\hline Production function & $\begin{array}{l}Y_{\mathrm{t}}=Z_{\mathrm{t}} K_{\mathrm{t}}^{\alpha} \bar{L}^{1-\alpha}\left(K_{\mathrm{RG}, \mathrm{t}}\right)^{\alpha_{\mathrm{G}}} \\
Y_{\mathrm{t}}^{*}=Z_{\mathrm{t}}^{*} K_{\mathrm{t}}^{* \alpha} \bar{L}^{*}{ }^{1-\alpha}\left(K_{\mathrm{RG}, \mathrm{t}}^{*}\right)^{\alpha_{\mathrm{G}}}\end{array}$ \\
\hline $\begin{array}{l}\text { Law of motion for private } \\
\text { capital }\end{array}$ & $\begin{array}{l}K_{\mathrm{t}}=I_{\mathrm{t}}+(1-\delta) K_{t-1} \\
K_{\mathrm{t}}^{*}=I_{\mathrm{t}}^{*}+(1-\delta) K_{t-1}^{*}\end{array}$ \\
\hline Consumption-Euler equation & $\begin{array}{l}\frac{\left(C_{\mathrm{t}}\right)^{-\gamma}}{E_{\mathrm{t}}\left[\left(C_{t+1}\right)^{-\gamma}\right]}=\beta E_{\mathrm{t}}\left[\left(1-\tau_{\mathrm{K}}\right) R_{t+1}+1-\delta\right] \\
\frac{\left(C_{\mathrm{t}}^{*}\right)^{-\gamma}}{E_{\mathrm{t}}\left[\left(C_{t+1}^{*}\right)^{-\gamma}\right]}=\beta E_{\mathrm{t}}\left[\left(1-\tau_{\mathrm{K}}\right) R_{t+1}^{*}+1-\delta\right]\end{array}$ \\
\hline Euler equation (private bonds) & $\begin{array}{l}\frac{\left(C_{t}\right)^{-\gamma}}{E_{t}\left[\left(C_{t+1}\right)^{-\gamma]}\right.}=\frac{\beta\left(1+R_{\mathrm{PRL}, t+1}\right)}{\left(1+\eta B_{t+1}\right)} \\
\frac{\left(C_{t}^{*}\right)^{-\gamma}}{E_{t}\left[\left(C_{t+1}^{*}\right)^{-\gamma}\right]}=\frac{\beta\left(1+R_{\mathrm{PR}, t+1}^{*}\right)}{\left(1+\eta B_{t+1}^{*}\right)}\end{array}$ \\
\hline $\begin{array}{l}\text { Euler equation (Region }(C, F) \\
\text { government bonds) }\end{array}$ & 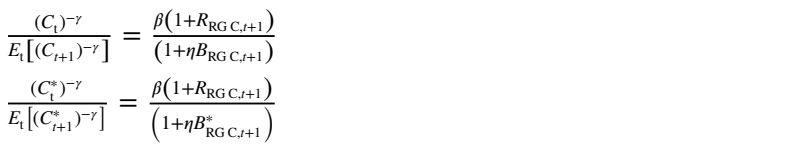 \\
\hline $\begin{array}{l}\text { Euler equation (Region }(L, F) \\
\text { government bonds) }\end{array}$ & $\begin{array}{l}\frac{\left(C_{C}\right)^{-\gamma}}{E_{\mathrm{t}}\left[\left(C_{t+1}\right)^{-\gamma}\right]}=\frac{\beta\left(1+R_{\mathrm{RG} \mathrm{L}, t+1}\right)}{\left(1+\eta B_{\mathrm{RG} \mathrm{L} \mathrm{Lt+1}}\right)} \\
\frac{\left(C_{t}^{*}\right)^{-\gamma}}{E_{\mathrm{t}}\left[\left(C_{t+1}^{*}\right)^{-\gamma]}\right]}=\frac{\beta\left(1+R_{\mathrm{RG} \mathrm{L}, t+1}\right)}{\left(1+\eta B_{\mathrm{RG} \mathrm{L} \mathrm{L,t+1}}^{*}\right)}\end{array}$ \\
\hline $\begin{array}{l}\text { Federal government budget } \\
\text { constraint }\end{array}$ & $\tau_{\mathrm{K}}\left(R_{\mathrm{t}} K_{\mathrm{t}}+R_{\mathrm{t}}^{*} K_{\mathrm{t}}^{*}\right)+\tau_{\mathrm{L}}^{\mathrm{FG}}\left(W_{\mathrm{t}} \bar{L}+W_{\mathrm{t}}^{*} \bar{L}^{*}\right)+T_{\mathrm{FG}, \mathrm{t}}+T_{\mathrm{FG}, \mathrm{t}}^{*}=C_{\mathrm{G}}$ \\
\hline $\begin{array}{l}\text { Region }(C, R) \text { government } \\
\text { budget constraint }\end{array}$ & $\begin{array}{l}\tau_{\mathrm{C}} C_{\mathrm{t}}+T_{\mathrm{RG} \mathrm{C}, \mathrm{t}}=I_{\mathrm{RG}, \mathrm{t}} \\
I_{\mathrm{RG}, \mathrm{t}}=\underline{\min }\left\{\tau_{\mathrm{C}} C_{\mathrm{t}}, \overline{I_{\mathrm{RG}}}\right\}\end{array}$ \\
\hline $\begin{array}{l}\text { Region }(L, R) \text { government } \\
\text { budget constraint }\end{array}$ & $\begin{array}{l}\tau_{\mathrm{L}}^{\mathrm{RG}} W_{\mathrm{t}}^{*} \overline{L^{*}}+T_{\mathrm{RG} \mathrm{L}, \mathrm{t}}^{*}=I_{\mathrm{RG}, \mathrm{t}}^{*} \\
I_{\mathrm{RG}, \mathrm{t}}^{*}=\min \left\{\tau_{\mathrm{L}}^{\mathrm{RG}} W_{\mathrm{t}}^{*} \overline{L^{*}, \overline{I_{\mathrm{RG}}^{*}}}\right\}\end{array}$ \\
\hline $\begin{array}{l}\text { Region }(C, F) \text { government } \\
\text { budget constraint }\end{array}$ & $\begin{array}{l}\tau_{\mathrm{C}} C_{\mathrm{t}}+B_{\mathrm{RG} \mathrm{C}, t+1}+B_{\mathrm{RG} \mathrm{C}, t+1}^{*}+T_{\mathrm{RG} \mathrm{C}, \mathrm{t}} \\
=\overline{I_{\mathrm{RG}}}+\left(1+R_{\mathrm{RG} \mathrm{C}, \mathrm{t}}\right) B_{\mathrm{RG} \mathrm{C}, \mathrm{t}}+\left(1+R_{\mathrm{RG} \mathrm{C}, \mathrm{t}}\right) B_{\mathrm{RG} \mathrm{C}, \mathrm{t}}^{*}\end{array}$ \\
\hline $\begin{array}{l}\text { Region }(L, F) \text { government } \\
\text { budget constraint }\end{array}$ & $\begin{array}{l}\tau_{\mathrm{L}}^{\mathrm{RG}} W_{\mathrm{t}}^{*} \overline{L^{*}}+B_{\mathrm{RG} \mathrm{L}, t+1}+B_{\mathrm{RG} \mathrm{L}, t+1}^{*}+T_{\mathrm{RG} \mathrm{L}, \mathrm{t}}^{*} \\
=\overline{I_{\mathrm{RG}}^{*}}+\left(1+R_{\mathrm{RG} \mathrm{L}, \mathrm{t}}\right) B_{\mathrm{RG} \mathrm{L}, \mathrm{t}}+\left(1+R_{\mathrm{RG} \mathrm{L}, \mathrm{t}}\right) B_{\mathrm{RG} \mathrm{L}, \mathrm{t}}^{*}\end{array}$ \\
\hline $\begin{array}{l}\text { Region }(C, F) \text { fiscal feedback } \\
\text { rule }\end{array}$ & $\begin{aligned} \frac{T_{\mathrm{RG} \mathrm{C}, \mathrm{t}}}{Y_{\mathrm{t}}} & =\frac{T_{\mathrm{RG} \mathrm{C}, t-1}}{Y_{t-1}}+l_{\mathrm{st}}\left(\frac{B_{\mathrm{RG} \mathrm{C}, t+1}+B_{\mathrm{RG} \mathrm{C}, t+1}^{*}}{Y_{\mathrm{t}}}-\frac{B_{\mathrm{RG} \mathrm{C} \text { tst }}+B_{\mathrm{RG} \mathrm{C} s t s t}^{*}}{Y_{\mathrm{stst}}}\right) \\
& +l_{\mathrm{gr}}\left(\frac{B_{\mathrm{RG} \mathrm{C}, t+1}+B_{\mathrm{RG} \mathrm{C}, t+1}^{*}}{Y_{\mathrm{t}}}-\frac{B_{\mathrm{RG} \mathrm{C}, \mathrm{t}}+B_{\mathrm{RG} \mathrm{C}, \mathrm{t}}^{*}}{Y_{t-1}}\right)\end{aligned}$ \\
\hline
\end{tabular}




\begin{tabular}{|c|c|}
\hline $\begin{array}{l}\text { Region }(L, F) \text { fiscal feedback } \\
\text { rule }\end{array}$ & $\begin{aligned} \frac{T_{\mathrm{RG} \mathrm{L}, \mathrm{t}}^{*}}{Y_{\mathrm{t}}^{*}} & =\frac{T_{\mathrm{RG} \mathrm{L}, t-1}^{*}}{Y_{t-1}^{*}}+l_{\mathrm{st}}\left(\frac{B_{\mathrm{RG} \mathrm{L}, t+1}+B_{\mathrm{RG} \mathrm{L}, t+1}^{*}}{Y_{\mathrm{t}}^{*}}-\frac{B_{\mathrm{RG} \mathrm{L} s t s t}+B_{\mathrm{RG} \mathrm{L} s t s t}^{*}}{Y_{\mathrm{stst}}^{*}}\right) \\
& +l_{\mathrm{gr}}\left(\frac{B_{\mathrm{RG} \mathrm{L}, t+1}+B_{\mathrm{RG} \mathrm{L}, t+1}^{*}}{Y_{\mathrm{t}}^{*}}-\frac{B_{\mathrm{RG} \mathrm{L}, \mathrm{t}}+B_{\mathrm{RG} \mathrm{L}, \mathrm{t}}^{*}}{Y_{t-1}^{*}}\right)\end{aligned}$ \\
\hline $\begin{array}{l}\text { Law of motion for public } \\
\text { capital }\end{array}$ & $\begin{aligned} K_{\mathrm{RG}, \mathrm{t}} & =I_{\mathrm{RG}, \mathrm{t}}+\left(1-\delta_{\mathrm{G}}\right) K_{\mathrm{RG}, t-1} \\
K_{\mathrm{RG}, \mathrm{t}}^{*} & =I_{\mathrm{RG}, \mathrm{t}}^{*}+\left(1-\delta_{\mathrm{G}}\right) K_{\mathrm{RG}, t-1}^{*}\end{aligned}$ \\
\hline $\begin{array}{l}\text { Union resource constraint } \\
\text { Balance of trade }\end{array}$ & $\begin{array}{l}Y_{\mathrm{t}}+Y_{\mathrm{t}}^{*}=C_{\mathrm{t}}+C_{\mathrm{t}}^{*}+I_{\mathrm{t}}+I_{\mathrm{t}}^{*}+C_{\mathrm{G}}+I_{\mathrm{RG}, \mathrm{t}}+I_{\mathrm{RG}, \mathrm{t}}^{*} \\
\mathrm{BOT}_{\mathrm{t}}=Y_{\mathrm{t}}-C_{\mathrm{t}}-I_{\mathrm{t}}-0.5 C_{\mathrm{G}}-I_{\mathrm{RG}, \mathrm{t}} \\
\mathrm{BOT}_{\mathrm{t}}^{*}=Y_{\mathrm{t}}^{*}-C_{\mathrm{t}}^{*}-I_{\mathrm{t}}^{*}-0.5 C_{\mathrm{G}}-I_{\mathrm{RG}, \mathrm{t}}^{*}\end{array}$ \\
\hline $\begin{array}{l}\text { Region } 1 \text { net regional asset } \\
\text { accumulation }\end{array}$ & $\begin{array}{r}B_{t+1}-\left(1+R_{\mathrm{PRI}, \mathrm{t}}\right) B_{\mathrm{t}}=\frac{1}{2}\left(R_{\mathrm{t}} K_{\mathrm{t}}-R_{\mathrm{t}}^{*} K_{\mathrm{t}}^{*}\right)+\frac{1}{2}\left(W_{\mathrm{t}} \bar{L}-W_{\mathrm{t}}^{*} \overline{L^{*}}\right) \\
-\frac{1}{2}\left(C_{\mathrm{t}}-C_{\mathrm{t}}^{*}\right)-\frac{1}{2}\left(I_{\mathrm{t}}-I_{\mathrm{t}}^{*}\right)-\frac{1}{2}\left(I_{\mathrm{RG}, \mathrm{t}}-I_{\mathrm{RG}}^{*}\right)\end{array}$ \\
\hline Bonds in zero net supply & $B_{\mathrm{t}}+B_{\mathrm{t}}^{*}=0$ \\
\hline Bivariate productivity process & {$\left[\begin{array}{c}Z_{\mathrm{t}} \\
Z_{\mathrm{t}}^{*}\end{array}\right]=\left[\begin{array}{cc}\phi_{Z} & \phi_{Z Z^{*}} \\
\phi_{Z^{*} Z} & \phi_{Z^{*}}\end{array}\right]\left[\begin{array}{c}Z_{t-1} \\
Z_{t-1}^{*}\end{array}\right]+\left[\begin{array}{c}\epsilon_{\mathrm{t}} \\
\epsilon_{\mathrm{t}}^{*}\end{array}\right]$} \\
\hline
\end{tabular}

\section{Appendix 3: Some results conditional on alternative technology process specification}

See Figs.7, 8, 9 and Table 9. 

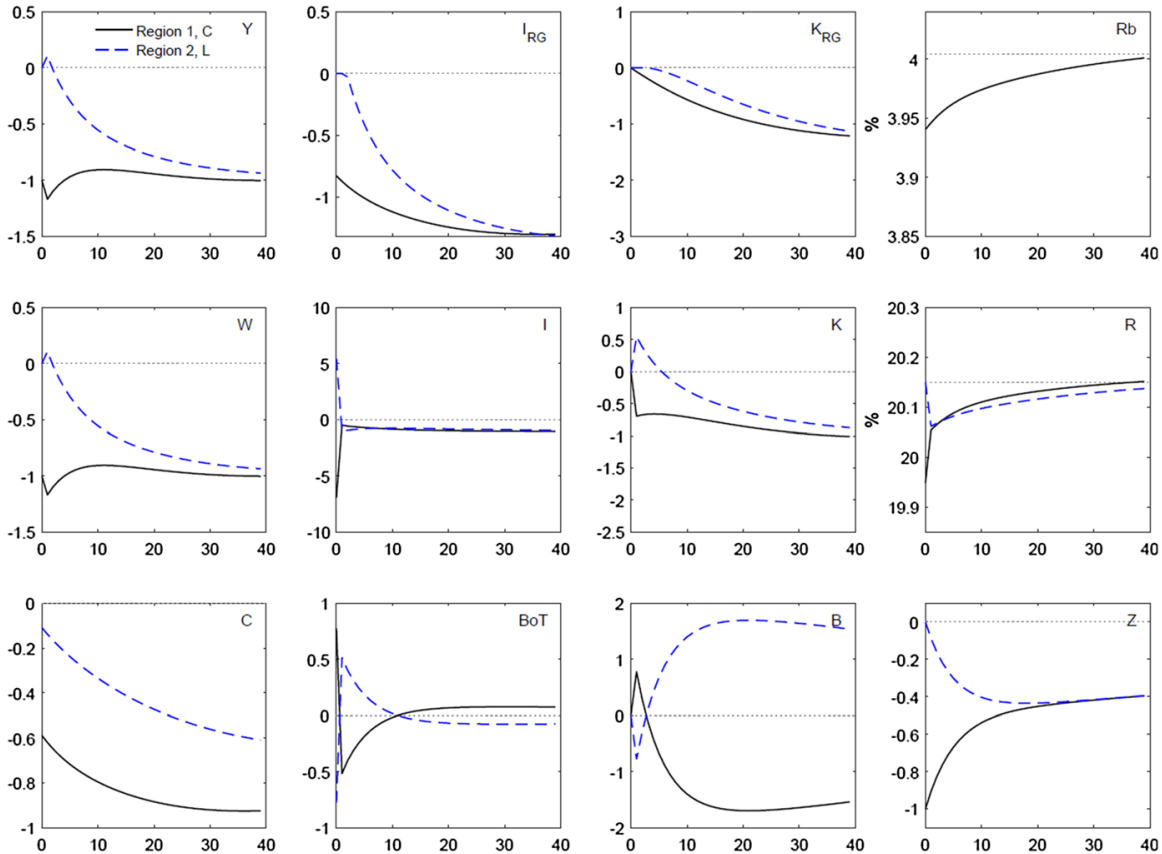

Fig. 7 Response of the endogenous variables to the idiosyncratic $-1 \%$ productivity shock to the $(C, R)$ region. Notes: The $U[(C, R),(L, R)]$ fiscal union is considered. The technology process with spillovers is adopted. Productivity of public goods is medium. The vertical axis measures percentage deviations of the endogenous variables from their respective steady states with the exception of the balance of trade and bonds measured relative to the steady-state output as well as the interest rate measured as percentages. The horizontal axis measures periods after the shock 

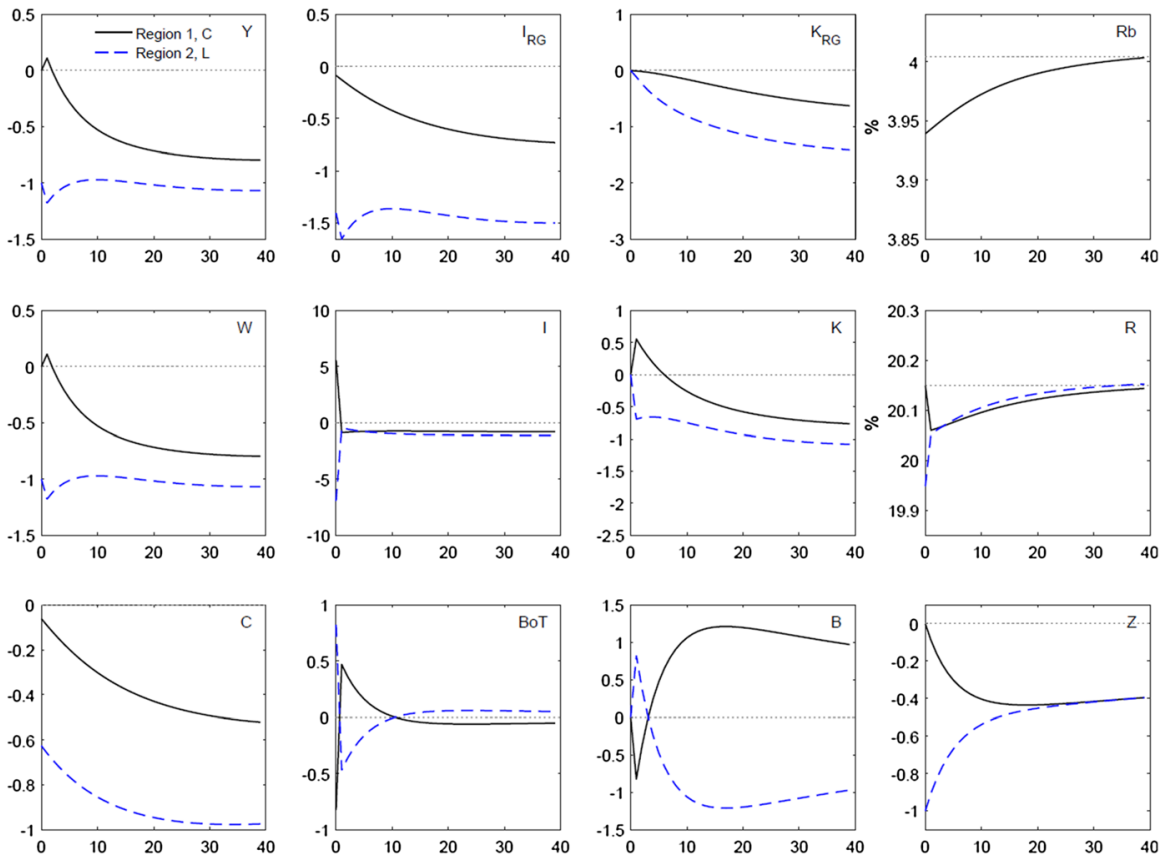

Fig. 8 Response of the endogenous variables to the idiosyncratic $-1 \%$ productivity shock to the $(L, R)$ region. Notes: The $U[(C, R),(L, R)]$ fiscal union is considered. The technology process with spillovers is adopted. Productivity of public goods is medium. The vertical axis measures percentage deviations of the endogenous variables from their respective steady states with the exception of the balance of trade and bonds measured relative to the steady-state output as well as the interest rate measured as percentages. The horizontal axis measures periods after the shock 
Panel A. Aggregate shock.
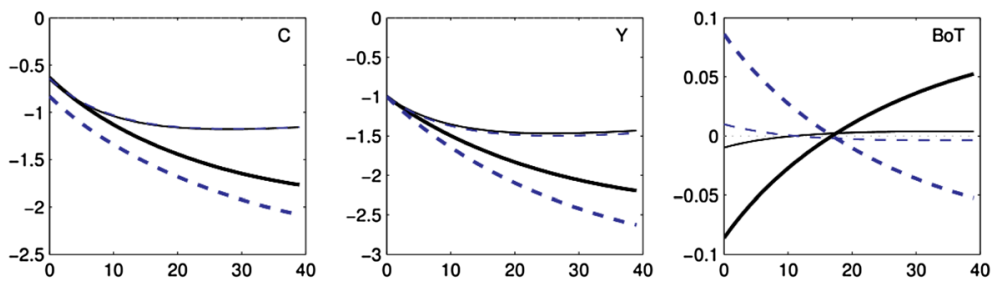

- Region $(C, R) \alpha_{G}=$ high; - - - Region $(L, R) \alpha_{G}=$ high; —_Region (C,R) $\alpha_{G}=$ very low; - - -Region (L,R) $\alpha_{G}=$ very low

Panel B. Idiosyncratic shock to the $(\boldsymbol{C}, \boldsymbol{R})$ region.
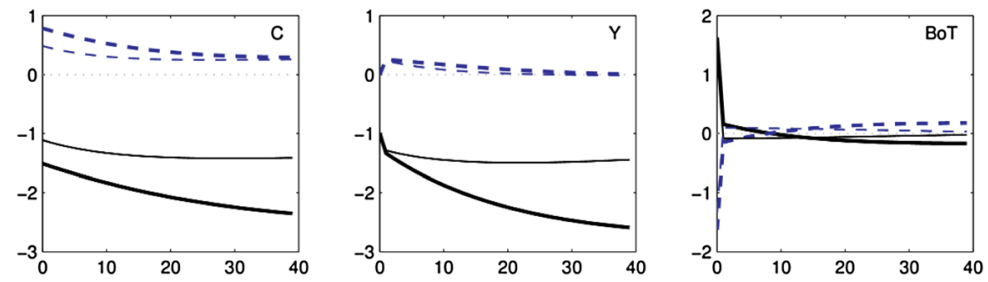

- Region $(C, R) \alpha_{G}=$ high; - - - Region $(L, R) \alpha_{G}=$ high; —_Region $(C, R) \alpha_{G}=$ very low; - - -Region $(L, R) \alpha_{G}=$ very low

Panel C. Idiosyncratic shock to the $(\boldsymbol{L}, \boldsymbol{R})$ region.
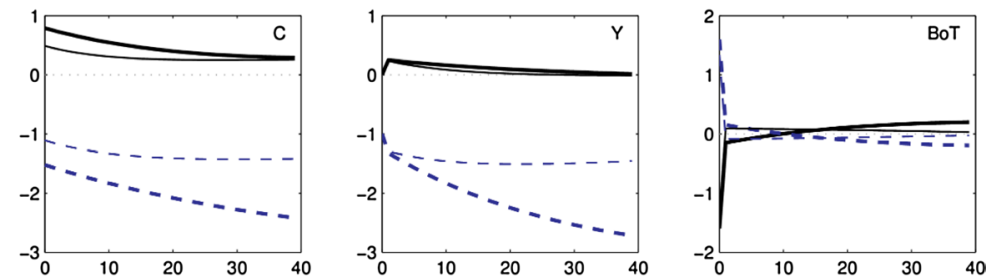

— Region $(C, R) \alpha_{G}=$ high; - - - Region $(L, R) \alpha_{G}=$ high; ——Region $(C, R) \alpha_{G}=$ very low; - - - Region $(L, R) \alpha_{G}=$ very low

Fig. 9 Responses of output, consumption, and investment to the $-1 \%$ productivity shocks under alternative assumptions about the productivity of public goods. Panel A. Aggregate shock. Panel B. Idiosyncratic shock to the $(C, R)$ region. Panel $\mathrm{C}$. Idiosyncratic shock to the $(L, R)$ region. The $U[(C, R),(L, R)]$ fiscal union is considered. The vertical axis measures percentage deviations of the variables from their respective steady states with the exception of the balance of trade measured relative to the steady-state output. The technology process without spillovers is adopted. The horizontal axis measures periods after the shock 


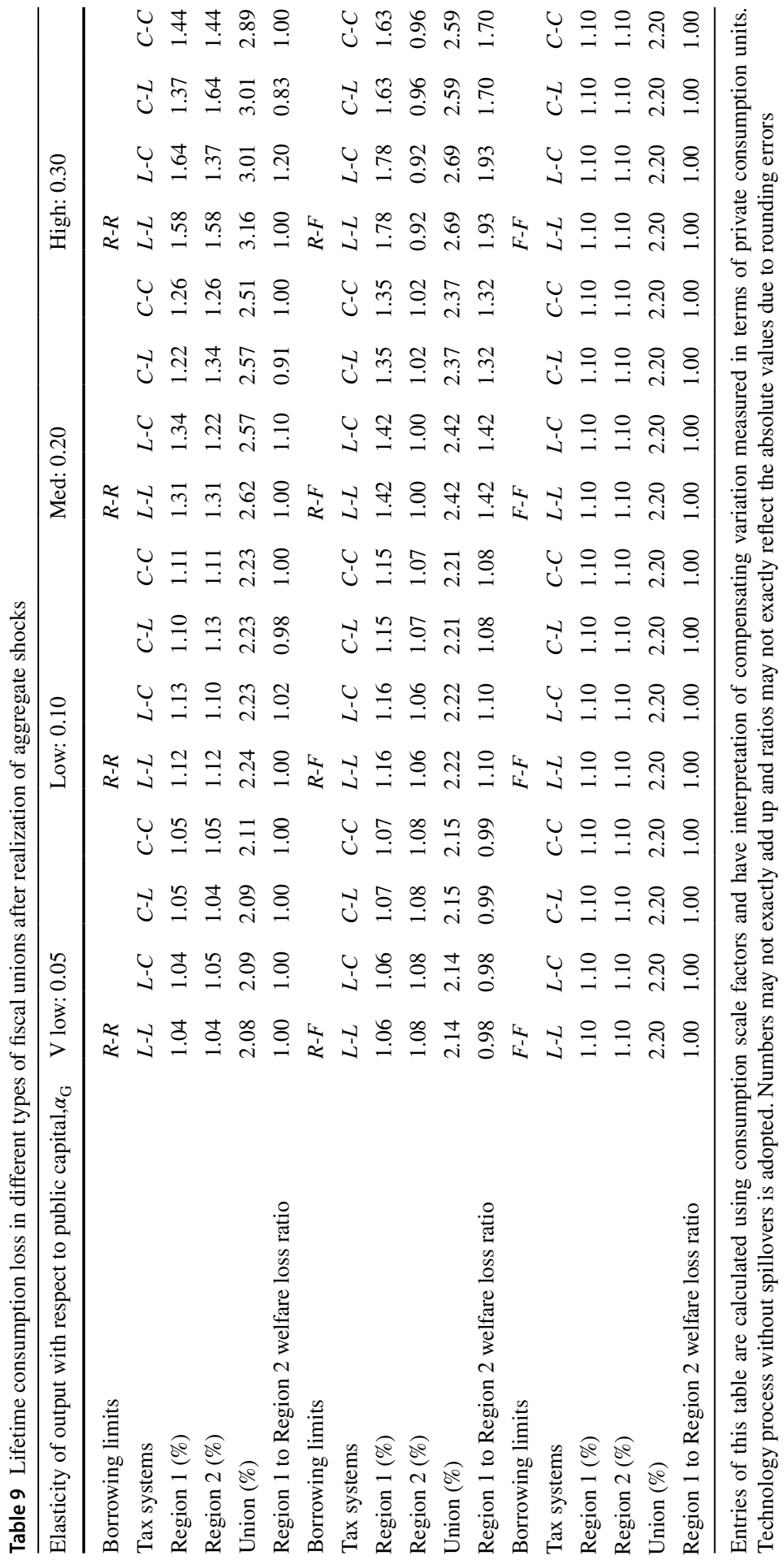


Acknowledgements The authors gratefully acknowledge comments they received from Oksana Leukhina, Christopher Otrok, Judith Thornton, and two anonymous referees, as well as participants of the Western Economic Association International conference, MTI seminars at the University of Washington, Albers scholarship seminars at Seattle University, Economics seminar at Portland State University, and Liberal arts macroeconomics workshop. Turnovsky wishes to acknowledge the support provided by the Van Voorhis foundation at the University of Washington.

\section{References}

ACIR, (1987). Fiscal discipline in the federal system: National reform and the experience of the States.

Aiyagari, S. R., Marcet, A., Sargent, T. J., \& Seppala, J. (2002). Optimal taxation without state- contingent debt. Journal of Political Economy, 110, 1220-1254.

Arcalean, C., Glomm, G., Schiopu, I., \& Suedekum, J. (2010). Public budget composition, fiscal (de) centralization, and welfare. Canadian Journal of Economics, 43(3), 832-859.

Aschauer, D. A. (1989). Is public expenditure productive? Journal of Monetary Economics, 23, 177-200.

Auray, S., Eyquem, A., \& Ma, X. (2017). Competitive tax reforms in a monetary union with endogenous entry and tradability. European Economic Review, 98, 126-143.

Backus, D. K., Kehoe, P. J., \& Kydland, F. E. (1992). International real business cycles. Journal of Political Economy, 100, 745-775.

Bassetto, M., \& Sargent, T. J. (2006). Politics and efficiency of separating capital and ordinary government budgets. Quarterly Journal of Economics, 121, 1167-1210.

Baxter, M., \& Farr, D. D. (2005). Variable capital utilization and international business cycles. Journal of International Economics, 65, 335-347.

Bayindir-Upmann, T. (1998). Two games of interjurisdictional competition when local governments provide industrial public goods. International Tax and Public Finance, 5, 471-487.

Benigno, P. (2009). Price stability with imperfect financial integration. Journal of Money, Credit and Banking, 41, 121-149.

Bom, P., \& Ligthart, J. (2014). What have we learned from three decades of research on the productivity of public capital? Journal of Economic Surveys, 28, 889-916.

Cacciatore, M. (2014). International trade and macroeconomic dynamics with labor market frictions. Journal of International Economics, 93, 17-30.

Dai, D., Liu, L., \& Tian, G. (2019a). Interregional redistribution and budget institutions with private information on intergenerational externality. Review of Economic Design, 23(3), 127-154.

Dai, D., Liu, L., \& Tian, G. (2019b). Optimal interregional redistribution and local borrowing rules under migration and asymmetric information. Journal of Public Economic Theory, 21(6), 1266-1285.

Dashkeev, V. V., \& Turnovsky, S. J. (2018). Balanced-budget rules and risk sharing in a fiscal union. Journal of Macroeconomics, 57, 277-298.

Dmitriev, M., \& Hoddenbagh, J. (2019). Optimal fiscal transfers in a monetary union. Journal of International Economics, 117, 91-108.

Economides, G., Park, H., \& Philippopoulos, A. (2011). How should the government allocate its tax revenues between productivity-enhancing and utility-enhancing public goods? Macroeconomic Dynamics, 15, 336-364.

Eicher, T., \& Turnovsky, S. J. (2000). Scale, congestion and growth. Economica, 67, 325-346.

Erceg, C. J., Guerrieri, L., \& Gust, C. (2006). SIGMA: A new open economy model for policy analysis. International Journal of Central Banking, 2, 1-50.

Evans, P., \& Karras, G. (1994). Are government activities productive? Evidence from a panel of U.S. states. Review of Economics and Statistics, 76, 1-11.

Farhi, E., Gopinath, G., \& Itskhoki, O. (2014). Fiscal devaluations. Review of Economic Studies, 81, $725-760$.

Farhi, E., \& Werning, I. (2017). Fiscal unions. American Economic Review, 107, 3788-3834.

Finn, M. (1993). Is all government capital productive?. Federal Reserve Bank of Richmond Economic Quarterly, (Fall), 53-80.

Ghironi, F. (2006). Macroeconomic interdependence under incomplete markets. Journal of International Economics, 70, 428-450. 
Guerrieri, L., \& Iacoviello, M. (2015). OccBin: A toolkit for solving dynamic models with occasionally binding constraints easily. Journal of Monetary Economics, 70, 22-38.

Guvenen, F. (2006). Reconciling conflicting evidence on the elasticity of intertemporal substitution: A macroeconomic perspective. Journal of Monetary Economics, 53, 1451-1472.

Heathcote, J., \& Perri, F. (2002). Financial autarky and international business cycles. Journal of Monetary Economics, 49, 601-627.

Huber, B., \& Runkel, M. (2008). Interregional redistribution and budget institutions under asymmetric information. Journal of Public Economics, 92(12), 2350-2361.

Joines, D. H. (1981). Estimates of effective marginal tax rates on factor incomes. The Journal of Business, 54, 191-226.

Jones, J. B. (2002). Has fiscal policy helped stabilize the postwar U.S. economy? Journal of Monetary Economics, 49, 709-746.

Keen, M., \& Marchand, M. (1997). Fiscal competition and the pattern of public spending. Journal of Public Economics, 66, 33-53.

Kenen, P. (1969). The theory of optimum currency areas: An eclectic view. In Mundell, R., and Swoboda, A. (Eds.) Monetary problems of the international economy. University of Chicago Press.

Leeper, E., Walker, T., \& Yang, S.-C. (2010). Government investment and fiscal stimulus. Journal of Monetary Economics, 57, 1000-1012.

McKinnon, R. I. (1963). Optimum currency areas. American Economic Review, 53, 717-725.

Mendoza, E. G., Razin, A., \& Tesar, L. L. (1994). Effective tax rates in macroeconomics: Cross-country estimates of tax rates on factor incomes and consumption. Journal of Monetary Economics, 34, 297-323.

Mendoza, E. G., \& Tesar, L. L. (2005). Why hasn’t tax competition triggered a race to the bottom? Some quantitative lessons from the EU. Journal of Monetary Economics, 52, 163-204.

Mundell, R. A. (1961). A theory of optimum currency areas. American Economic Review, 51, 657-665.

Oates, W. E. (1972). Fiscal federalism. Harcourt Brace Jovanovich.

Oates, W. E. (1999). An essay on fiscal federalism. Journal of Economic Literature, 37, 1120-1149.

Oates, W. E. (2005). Toward a second-generation theory of fiscal federalism. International Tax and Public Finance, 12, 349-373.

Pappa, E. (2009). The effects of fiscal shocks on employment and the real wage. International Economic Review, 50, 217-244.

Poterba, J. M. (1995). Balanced budget rules and fiscal policy: Evidence from the States. National Tax Journal, 48, 329-336.

Sorensen, B. E., \& Yosha, O. (2001). Is state fiscal policy asymmetric over the business cycle? Federal Reserve Bank of Kansas Economic Review, 8, 43-64.

Stockman, D. R. (2001). Balanced-budget rules: Welfare loss and optimal policies. Review of Economic Dynamics, 4, 438-459.

Tiebout, C. M. (1956). A pure theory of local expenditures. Journal of Political Economy, 64, 416-424.

Turnovsky, S. J. (1985). Domestic and foreign disturbances in an optimizing model of exchange-rate determination. Journal of International Money and Finance, 4, 151-171.

Turnovsky, S. J., \& Fisher, W. H. (1995). The composition of government expenditure and its consequences for macroeconomic performance. Journal of Economic Dynamics and Control, 19, $747-786$.

Wilson, J. D. (1999). Theories of tax competition. National Tax Journal, 52, 269-304.

Zodrow, G. R., \& Mieszkowski, P. (1986). Pigou, Tiebout, property taxation, and the underprovision of local public goods. Journal of Urban Economics, 3, 356-370.

Publisher's Note Springer Nature remains neutral with regard to jurisdictional claims in published maps and institutional affiliations. 